\title{
Structure Activity Relationship Study of the XIP Quorum Sensing Pheromone in Streptococcus mutans Reveal Inhibitors of the Competence Regulon
}

\author{
Chowdhury Raihan Bikash and Yftah Tal-Gan* \\ Department of Chemistry, University of Nevada, Reno, 1664 North Virginia Street, Reno, \\ NV 89557
}

Supporting Information.

Additional experimental details........................................................ S-2

HPLC traces for XIP analogs.......................................................... S

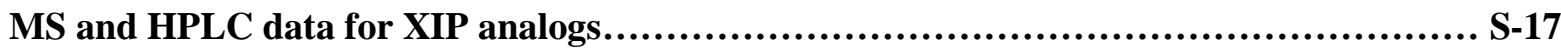

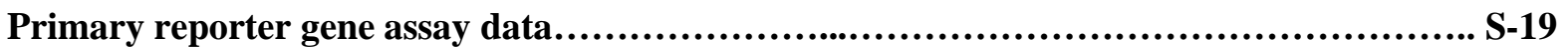

Dose response curves.................................................................... S-22

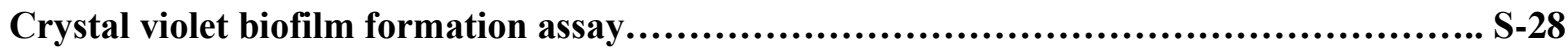

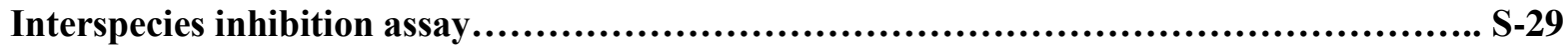

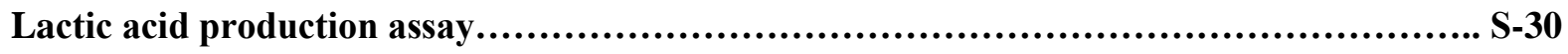

\footnotetext{
* To whom correspondence should be addressed. ytalgan@unr.edu
} 


\section{$\underline{\text { Additional experimental details }}$}

\section{Peptide synthesis}

Solid Phase Peptide Synthesis. All the XIP analogs were synthesized using standard Fmoc-based solidphase peptide synthesis (SPPS) procedures on 4-benzyloxybenzyl alcohol (Wang) resin. Loading of the first amino acid to the Wang resin linker was done by using the symmetrical anhydride procedure as described below.

Loading to Resin. $0.1 \mathrm{~g}$ of Wang resin $(0.94 \mathrm{mmol} / \mathrm{g})$ was placed in a clean, dry round bottom flask with a minimal amount of DMF to fully cover the resin, and the resin was allowed to swell at room temperature for $30 \mathrm{~min}$. $0.94 \mathrm{mmol}$ (10 equiv. relative to the overall loading of the resin) of Fmoc-protected amino acid were dissolved in dry DCM and placed on an ice bath. A few drops of DMF were added to aid complete dissolution when the amino acid had low solubility in DCM. A solution of $0.47 \mathrm{mmol}$ (5 equiv. relative to the overall loading of the resin) diisopropylcarbodiimide (DIC) in dry DCM was then added dropwise to the amino acid solution. The mixture was stirred for $20 \mathrm{~min}$ on an ice bath and the DCM was removed from the mixture using a rotary evaporator. The residue was then dissolved with a minimal amount of DMF and the solution was added to the resin. $0.0094 \mathrm{mmol}$ ( 0.1 equiv. relative to the overall loading of the resin) of dimethylaminopyridine (DMAP) were dissolved in DMF and the solution was added to the reaction mixture. The mixture was sealed and allowed to stand at room temperature for $2 \mathrm{~h}$ with occasional swirling. The resin was washed with DCM, then diethyl ether, followed by overnight drying under vacuum.

Loading Test. Two small samples of the amino acid-loaded resin (approximately $5 \mathrm{mg}$ each) were weighed and mixed with $3 \mathrm{~mL}$ of fresh 20\% piperidine in DMF solution. This solution was stirred on a shaker for 2 $\mathrm{h}$. The absorbance $(290 \mathrm{~nm})$ of the supernatants of the two piperidine-resin mixtures was measured by using a UV-Vis spectrophotometer to estimate the level of Fmoc removal, which correlates to first residue attachment. The first residue attachment was estimated from the following equations:

\section{Equation $1 \quad A(\mathrm{mmol} / \mathrm{g})=B \times 1000 /[1000+(B \times(M-X))]$}

A is the theoretical substitution ( $\mathrm{mmol} / \mathrm{g}$ ), B is the substitution of starting resin $(\mathrm{mmol} / \mathrm{g}$ ), and $\mathrm{M}$ is the molecular weight of target peptide with all protecting groups. $\mathrm{X}$ is 18 for hydroxymethyl-based resin.

Equation $2 \quad B(\mathrm{mmol} / \mathrm{g})=\left(\right.$ Abs sample $\left._{\text {s }} \mathrm{N}\right) /(\mathrm{mg}$ of sample $\times 1.75)$

$\mathrm{B}$ is the experimental first residue attachment and the equation is based on $\varepsilon=5253 \mathrm{M}^{-1} \mathrm{~cm}^{-1}$. N is the fold of dilution of the supernatant. $\frac{\mathrm{B}}{\mathrm{A}} \times 100 \%$ is the percent yield of the loading. If the average of the percent yield of the two samples was greater than $70 \%$, resin loading was deemed successful and the resin would be used for the synthesis of XIP analogs.

Synthesis. XIP and XIP analogs were synthesized with the Liberty 1 automated peptide synthesizer (CEM Corporation) (Coupling, $75{ }^{\circ} \mathrm{C} / 5 \mathrm{~min}$ and Deprotection, $90{ }^{\circ} \mathrm{C} / 90 \mathrm{sec}$ ). For the deprotection, 20\% piperidine in DMF was used and for the coupling, Fmoc-protected amino acids (5 equiv.), 2-(1Hbenzotriazol-1-yl)-1,1,3,3-tetramethyluronium hexafluorophosphate (HBTU; 5 equiv.) and diisopropylethylamine (DIPEA; 10 equiv.) were used.

Cleavage. Upon completion of peptide synthesis, the resin was washed with diethyl ether $(2 \mathrm{~mL})$ and dried under nitrogen stream for 3 min before it was transferred into a $15 \mathrm{~mL}$ falcon tube. The peptide was cleaved from the resin, along with all of the protecting groups, by mixing the resin with $3 \mathrm{~mL}$ cleavage cocktail of 95\% trifluoroacetic acid (TFA), 2.5\% triisopropylsilane (TIPS), and 2.5\% $18 \mathrm{M} \Omega$ water for $3 \mathrm{~h}$ with agitation. The resulting cleavage product solution was separated from the resin by filtration and the filtrate was transferred into a new $50 \mathrm{~mL}$ falcon tube. A cooled solution of diethyl ether:hexane $\left(1: 1,45 \mathrm{~mL}, 0{ }^{\circ} \mathrm{C}\right)$ was added to the filtrate, and the peptide was allowed to precipitate for $10 \mathrm{~min}$ in a freezer at $-20{ }^{\circ} \mathrm{C}$. The mixture was centrifuged for $5 \mathrm{~min}$ at $3000 \mathrm{RPM}$ and the supernatant was removed to yield crude peptide that was dissolved in $10 \mathrm{~mL}$ acetonitrile (ACN):water (1:1) and lyophilized before HPLC purification. 
Peptide Purification. Crude peptides were purified with RP-HPLC. A semipreparative Phenomenex Kinetex C18 column $(5 \mu \mathrm{m}, 10 \mathrm{~mm} \times 250 \mathrm{~mm}, 110 \AA$ ) was used for preparative RP-HPLC work, while an analytical Phenomenex Kinetex C18 column $(5 \mu \mathrm{m}, 4.6 \mathrm{~mm} \times 250 \mathrm{~mm}, 110 \AA)$ was used for analytical RPHPLC work. Standard RP-HPLC conditions were as follows: flow rates $=5 \mathrm{~mL} \mathrm{~min}{ }^{-1}$ for semipreparative separations and $1 \mathrm{~mL} \mathrm{~min}^{-1}$ for analytical separations; mobile phase $\mathrm{A}=18 \mathrm{M} \Omega$ water $+0.1 \% \mathrm{TFA}$; mobile phase $\mathrm{B}=\mathrm{ACN}+0.1 \%$ TFA. Purities were determined by integration of peaks with UV detection at 220 $\mathrm{nm}$. Preparative HPLC methods were used to separate the crude peptide mixture to different chemical components using a linear gradient (first prep 5\% B $\rightarrow 45 \% \mathrm{~B}$ over $40 \mathrm{~min}$ and second prep $20 \% \mathrm{~B} \rightarrow 30 \%$ $\mathrm{B}$ over $30 \mathrm{~min}$ ), except for the di- and tri-peptide analogs. A different linear gradient $(5 \% \mathrm{~B} \rightarrow 25 \% \mathrm{~B}$ over $40 \mathrm{~min}$ ) was used for prep purifications of the di- and tri-peptide analogs (a single prep run was sufficient to purify the di- and tri-peptides to $>95 \%$ purity). Then, an analytical HPLC method was used to quantify the purity of the desired product using a linear gradient $(5 \% \mathrm{~B} \rightarrow 95 \% \mathrm{~B}$ over $27 \mathrm{~min})$. Only peptide fractions that were purified to homogeneity $(>95 \%)$ were used for the biological assays. Exact Mass was used to validate the presence of synthesized peptides. The observed mass-to-charge $(\mathrm{m} / \mathrm{z})$ ratio of the peptide was compared to the expected $\mathrm{m} / \mathrm{z}$ ratio for each peptide.

\section{Biological assays}

Bacterial Growth Conditions for CDM. Bacteria from freezer stocks were streaked onto a THY agar plate containing $5 \mu \mathrm{g} / \mathrm{mL}$ erythromycin (S. mutans SMCOM2) or $250 \mu \mathrm{g} / \mathrm{mL}$ kanamycin (S. mutans $\mathrm{SAB} 249)$. The plate was incubated for $22-24 \mathrm{~h}$ in a $\mathrm{CO}_{2}$ incubator $\left(37{ }^{\circ} \mathrm{C}\right.$ with $\left.5 \% \mathrm{CO}_{2}\right)$. A fresh single colony was transferred to $5 \mathrm{~mL}$ of BHI broth supplemented with a final concentration of $5 \mu \mathrm{g} / \mathrm{mL}$ erythromycin ( $S$. mutans SMCOM2) or $250 \mu \mathrm{g} / \mathrm{mL}$ kanamycin $(S$. mutans SAB249) and the culture was incubated in a $\mathrm{CO}_{2}$ incubator overnight $(15 \mathrm{~h})$. Overnight culture was then diluted 1:25 with $\mathrm{BHI}$, and the resulting solution was incubated in a $\mathrm{CO}_{2}$ incubator for $2.5 \mathrm{~h}$, until the bacteria reached early exponential stage $(0.15-0.16$ OD $600 \mathrm{~nm})$ as determined by using a plate reader. After that, cells were centrifuged at $5000 \mathrm{rpm}$ for $10 \mathrm{~min}$ and BHI medium was discarded. Then, cells were washed and centrifuged (5 min at $5000 \mathrm{rpm}$ ) two times with $5 \mathrm{~mL}$ sterile PBS buffer. PBS buffer was discarded and the cells were resuspended in CDM media and vortexed for $10 \mathrm{sec}$ followed by $25 \mathrm{~min}$ incubation in a shaking incubator at $37^{\circ} \mathrm{C}$ to allow the bacteria cells to adapt to the new media environment before they were used in the different CDM assays.

Beta-Galactosidase Activation Assays in CDM. The ability of synthetic XIP analogs to activate the expression of $\operatorname{com} X$ was determined using the $S$. mutans SMCOM2 reporter strain in CDM (S. mutans SAB249 reporter strain was only used to check the inhibitory activity of the lead inhibitor in presence of CSP and XIP). An initial activation screening was performed at a high concentration $(100 \mu \mathrm{M})$ for all XIP analogs. A total of $2 \mu \mathrm{L}$ of $10 \mathrm{mM}$ solution of XIP analogs in dimethyl sulfoxide (DMSO) was added in triplicate to a clear 96-well microtiter plate. This concentration was chosen to afford full activation of the QS circuit, as determined from the dose-dependent curve created for the native XIP. A total of $2 \mu \mathrm{L}$ of DMSO was added in triplicate and served as the negative control, while $2 \mu \mathrm{L}$ of native XIP in DMSO was added in triplicate and served as the positive control. Then, $198 \mu \mathrm{L}$ of bacterial culture in CDM was added to each well containing XIP and analogs. The plate was incubated at $37^{\circ} \mathrm{C}$ for $1 \mathrm{~h}$, and the OD $600_{\mathrm{nm}}$ was measured. In order to measure the beta-galactosidase activity in the culture, the cells were lysed by incubating the culture for $30 \mathrm{~min}$ at $37{ }^{\circ} \mathrm{C}$ with $20 \mu \mathrm{L}$ of $0.1 \%$ Triton X-100. In a new plate, $100 \mu \mathrm{L}$ of Zbuffer solution $\left(60.2 \mathrm{mM} \mathrm{Na}_{2} \mathrm{HPO}_{4}, 45.8 \mathrm{mM} \mathrm{NaH}_{2} \mathrm{PO}_{4}, 10 \mathrm{mM} \mathrm{KCl}\right.$, and $1.0 \mathrm{mM} \mathrm{MgSO}$ in $18 \mathrm{M} \Omega ~_{2} \mathrm{O}$; $\mathrm{pH}$ was adjusted to 7.0, and the buffer was sterilized before use) containing 2-nitrophenyl-beta-Dgalactopyranoside (ONPG) at a final concentration of $0.4 \mathrm{mg} \mathrm{mL}^{-1}$ was added, followed by $100 \mu \mathrm{L}$ of lysate, and the plate was incubated for $30 \mathrm{~min}$ at $37^{\circ} \mathrm{C}$. The reaction was stopped by adding $50 \mu \mathrm{L}$ of $1 \mathrm{M}$ sodium carbonate solution, and the OD $420_{\mathrm{nm}}$ and OD $550 \mathrm{~nm}$ were measured using a plate reader. The final results were reported as percent activation, which is the ratio between the Miller units of the analog and of the positive control. For calculation of Miller units, please see data analysis section below. Analogs that exhibited high activity in the initial screening (>50\% activation compared to the native signal; see Figures 
S-1 and S-2) were further evaluated using a dose-dependent assay in which peptide stock solutions were diluted with DMSO in serial dilutions (either 1:2, 1:3, or 1:5) and assayed as described above. GraphPad Prism 5 was used to calculate the $\mathrm{EC}_{50}$ values, which are the concentration of a drug that gives half-maximal response.

Beta-Galactosidase Inhibition Assays in CDM. Analogs that exhibited low $\operatorname{com} X$ activation in the initial screening (see Figure S-1 and S-2) were evaluated for competitive inhibition (see Figure S-3). The ability of synthetic XIP analogs to inhibit the expression of $\operatorname{com} X$ by outcompeting XIP for the ComR binding site was evaluated using the same assay conditions as described above, except that in the initial inhibition screening, the native XIP was added to every well in a set concentration ( $2000 \mathrm{nM}$ final concentration) that was chosen to afford full activation of the QS circuit, as determined from the dose-dependent curve created for the native XIP. A total of $2 \mu \mathrm{L}$ of $200 \mu \mathrm{M}$ solution of native XIP and $2 \mu \mathrm{L}$ of $10 \mathrm{mM}$ solution of XIP analogs were added to the same well in triplicate in a clear 96-well microtiter plate. A total of $2 \mu \mathrm{L}$ of native XIP and $2 \mu \mathrm{L}$ of DMSO were added to the same well in triplicate and served as the positive control. A total of $4 \mu \mathrm{L}$ of DMSO was added in triplicate and served as the negative control. Then, $196 \mu \mathrm{L}$ of bacterial culture in CDM was added to the wells, and the plate was incubated at $37{ }^{\circ} \mathrm{C}$ for $1 \mathrm{~h}$. The procedure for lysis, incubation with ONPG, and all the measurements were as described in the activation assay.

Bacterial Growth Conditions for complex media (THY). A fresh single colony was transferred to $5 \mathrm{~mL}$ of THY broth supplemented with a final concentration of $250 \mu \mathrm{g} / \mathrm{mL}$ kanamycin (S. mutans SAB249) or 5 $\mu \mathrm{g} / \mathrm{mL}$ erythromycin ( $S$. mutans SMCOM2) and the culture was incubated in a $\mathrm{CO}_{2}$ incubator overnight $(15 \mathrm{~h})$. Overnight culture was then diluted 1:25 with THY, and the resulting solution was incubated in a $\mathrm{CO}_{2}$ incubator for $2 \mathrm{~h}$, until the bacteria reached early exponential stage $(0.17-0.19)$ as determined by using a plate reader. 


\section{HPLC traces for XIP analogs}

\section{XIP (P1)}

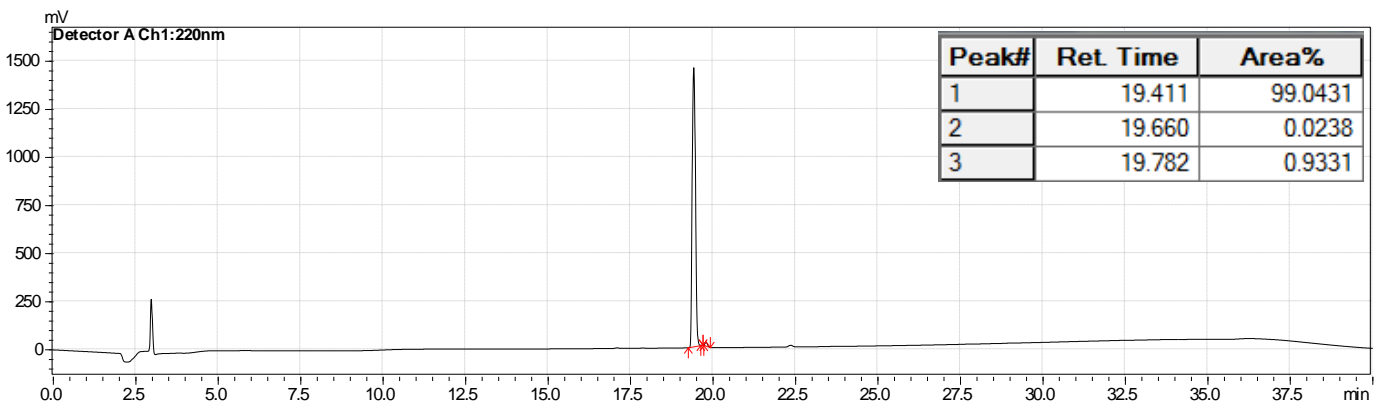

XIP-G1A (P2)

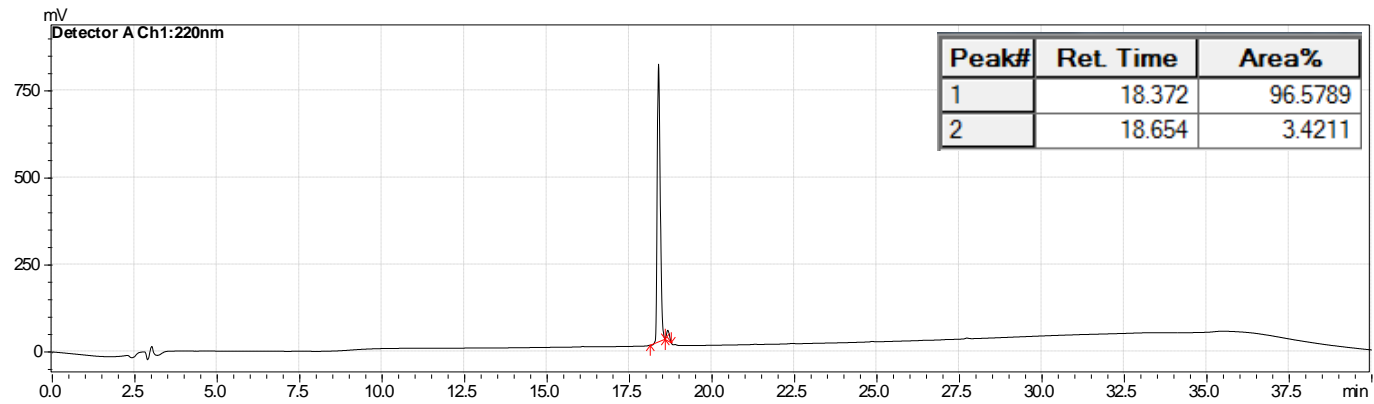

XIP-L2A (P3)

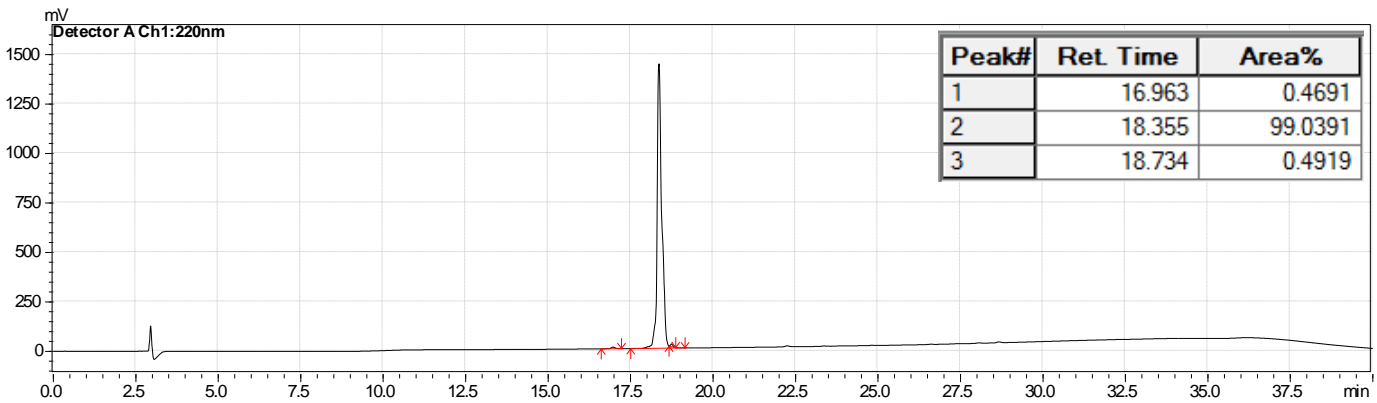

XIP-D3A (P4)

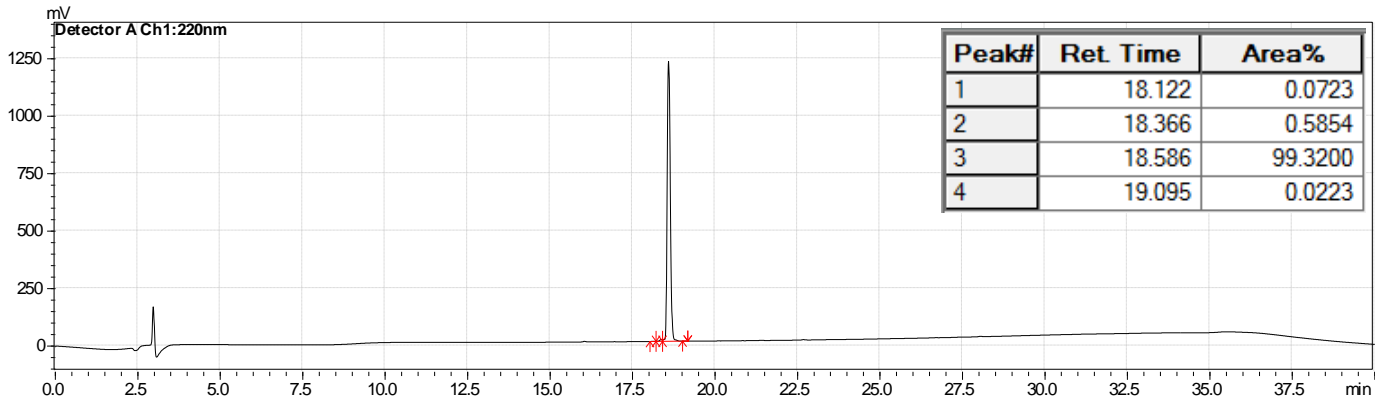




\section{XIP-W4A (P5)}

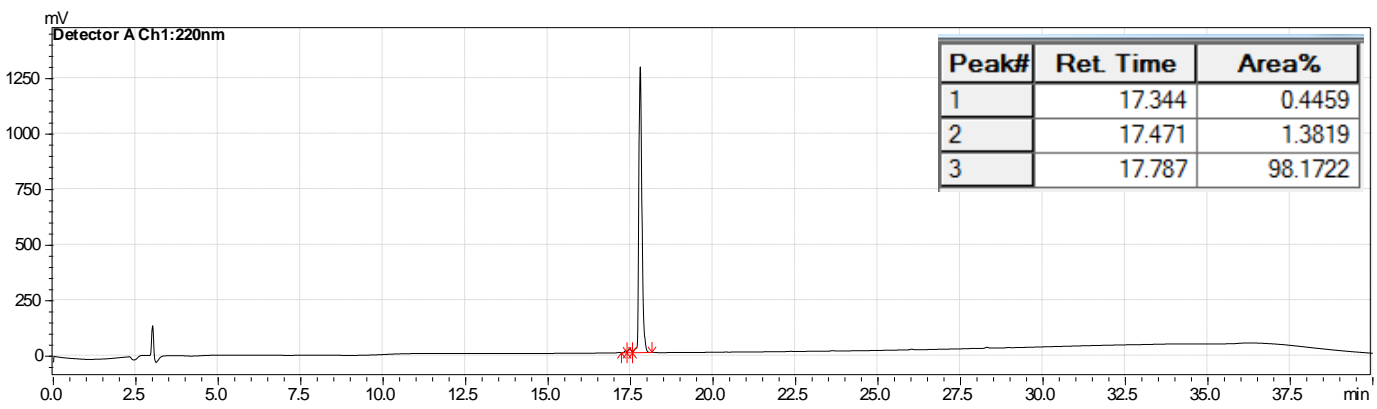

XIP-W5A (P6)

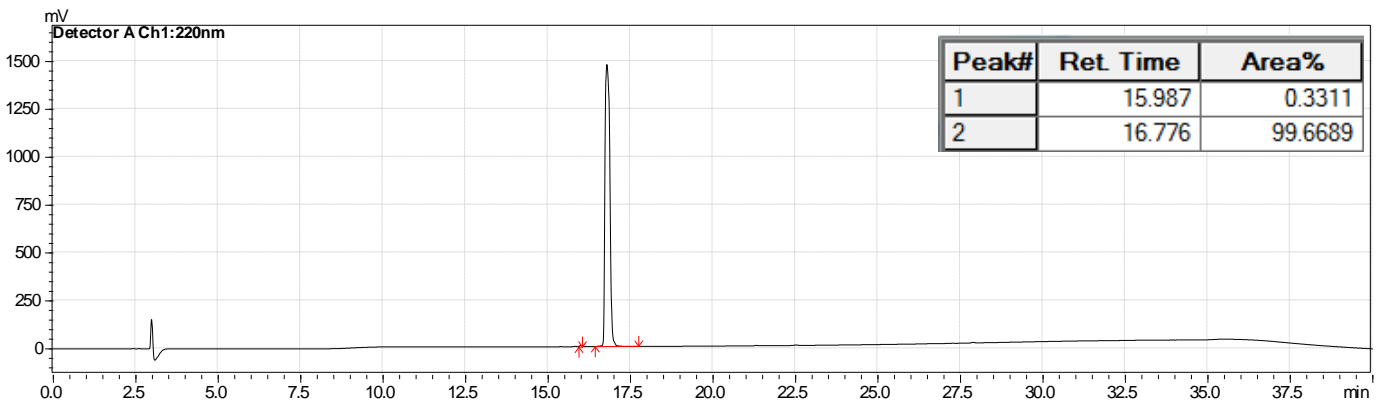

XIP-S6A (P7)

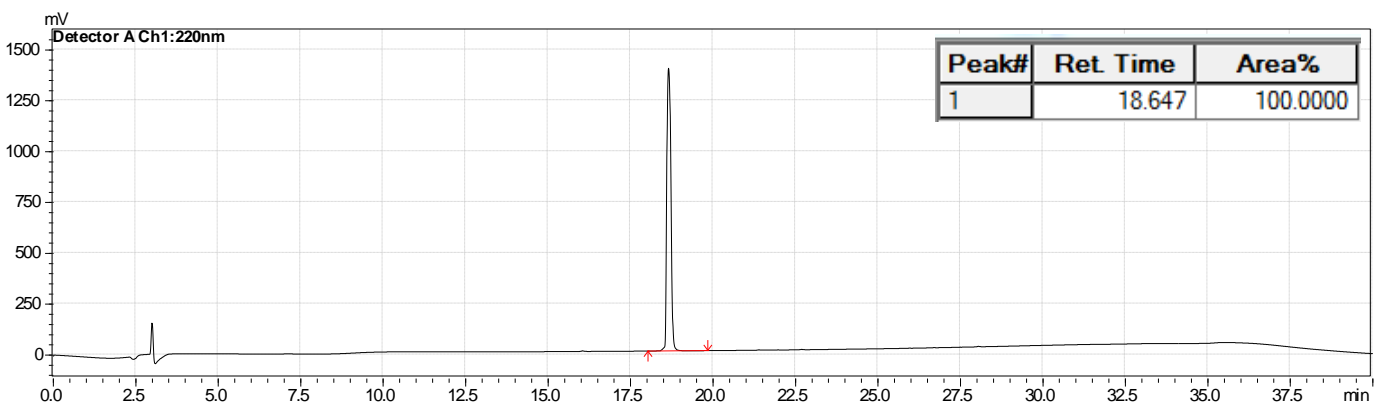

XIP-L7A (P8)

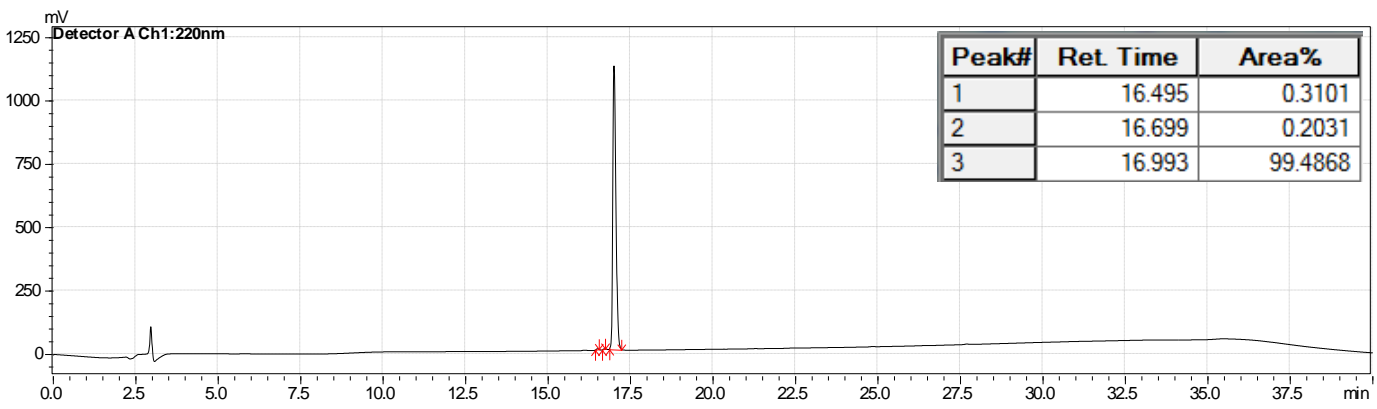


XIP-12 (P9)

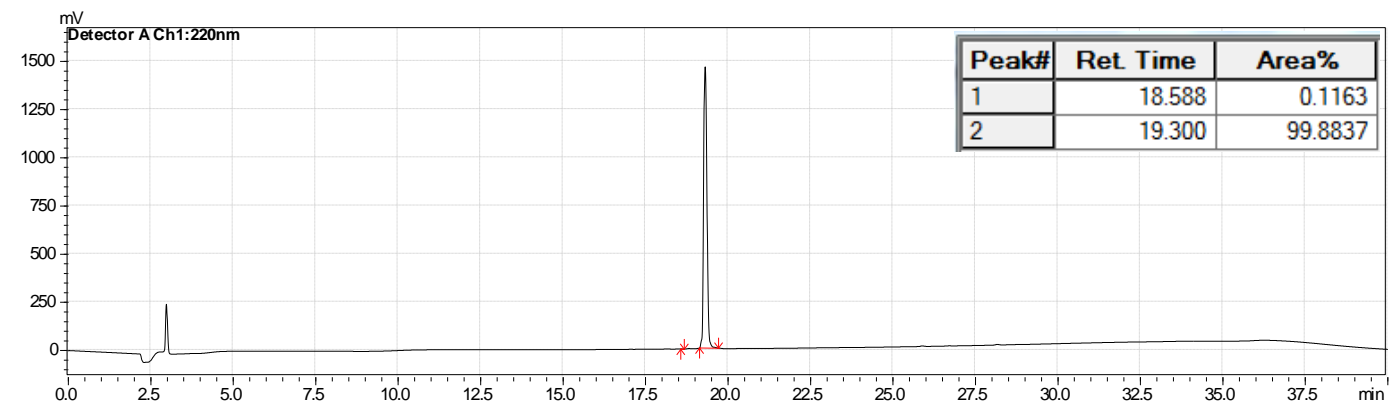

XIP-d3 (P10)

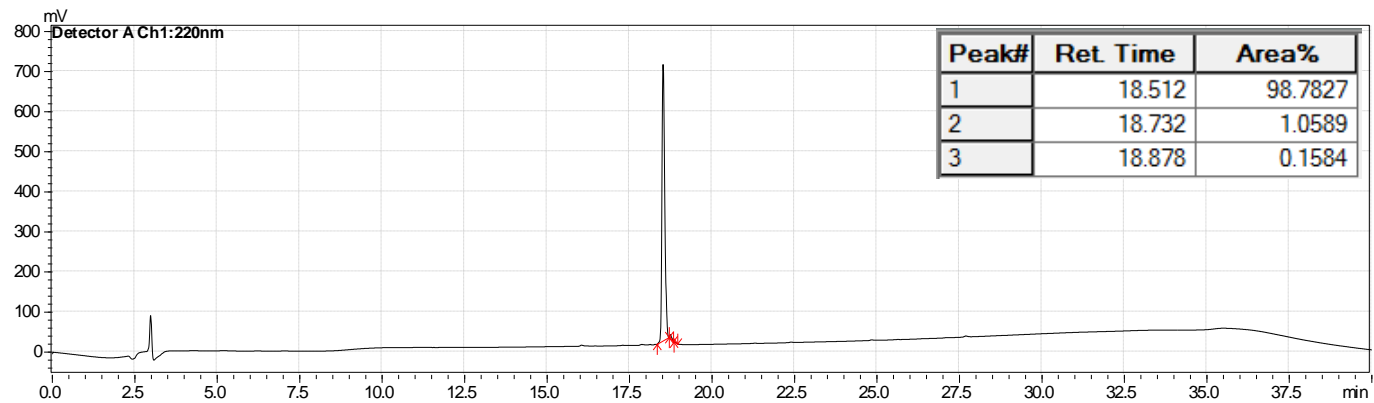

XIP-w4 (P11)

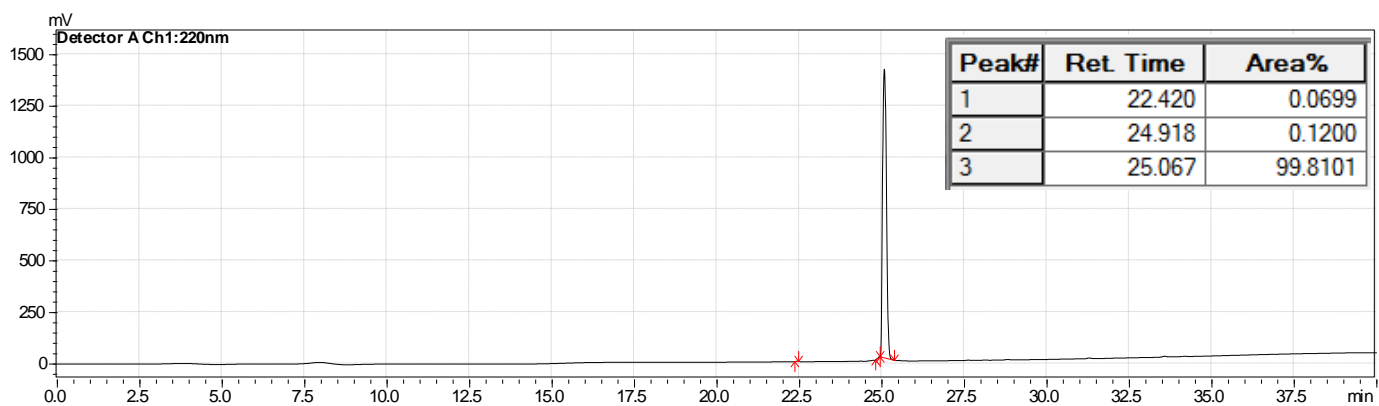

XIP-w5 (P12)

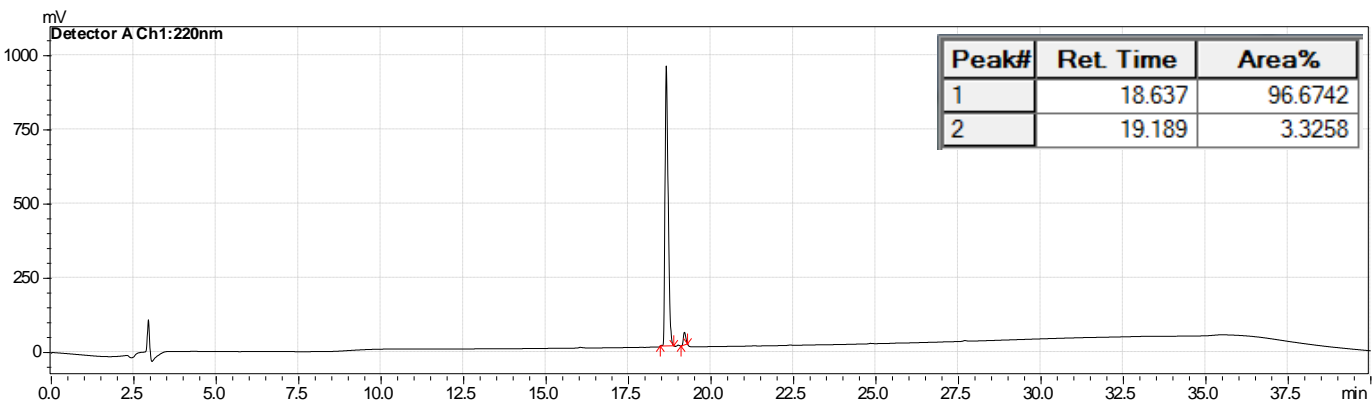


XIP-s6 (P13)

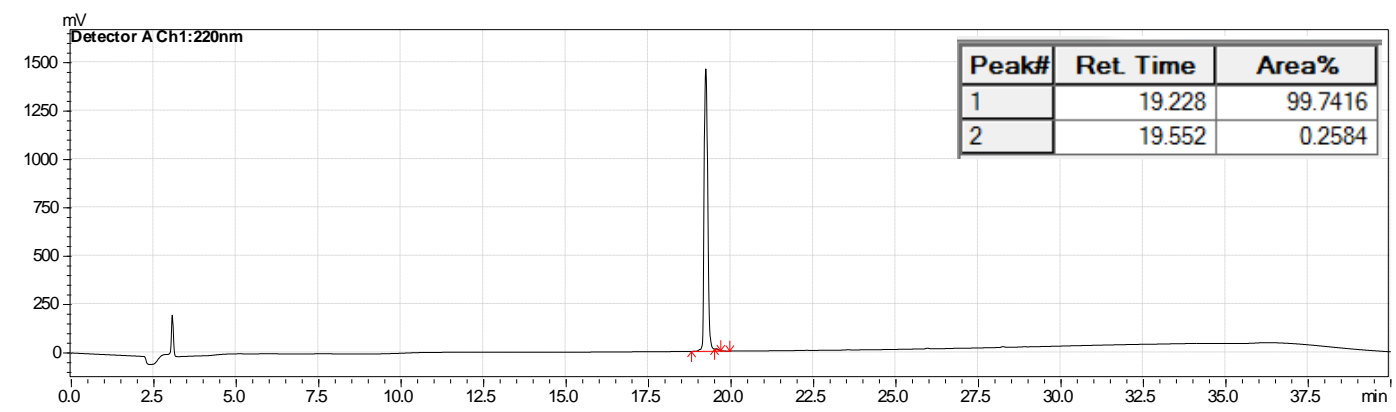

XIP-17 (P14)

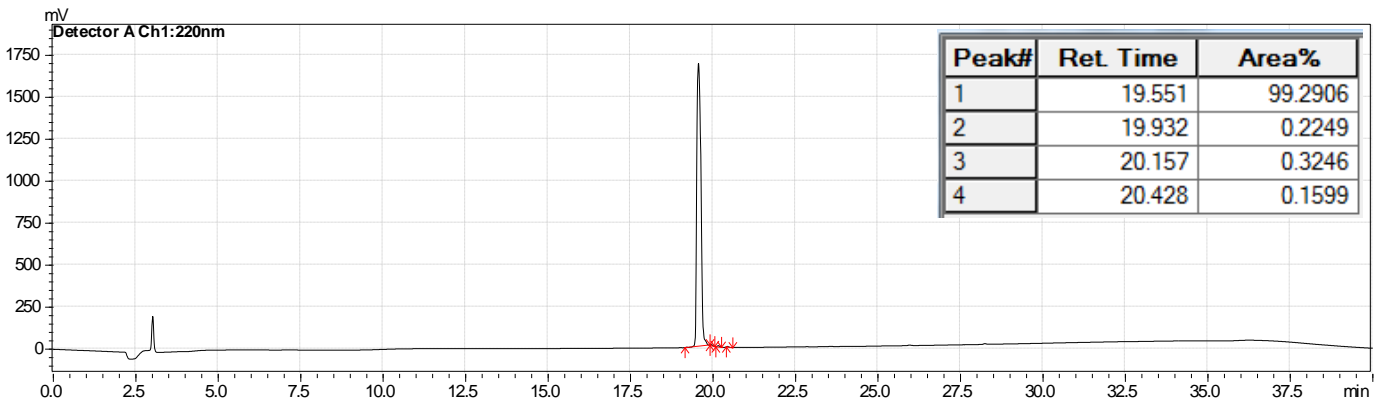

XIP-L2I (P15)

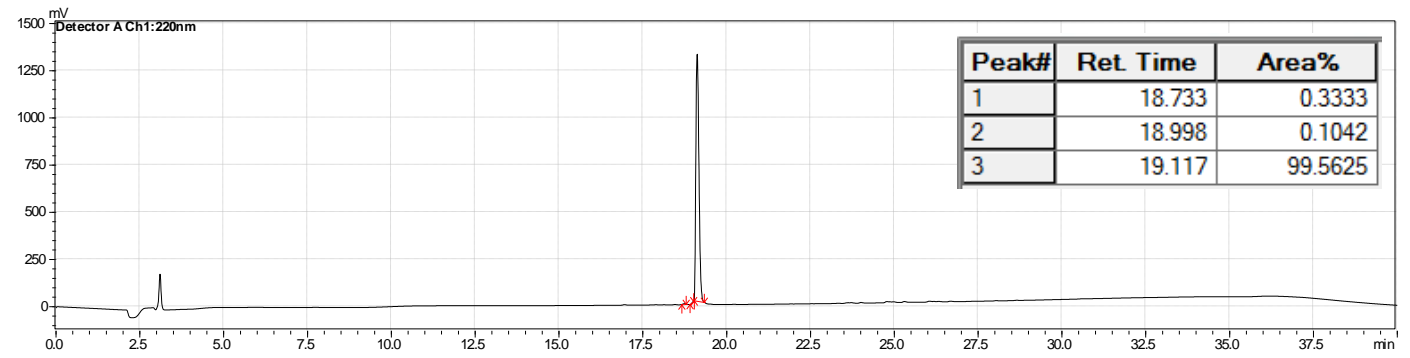

XIP-L2V (P16)

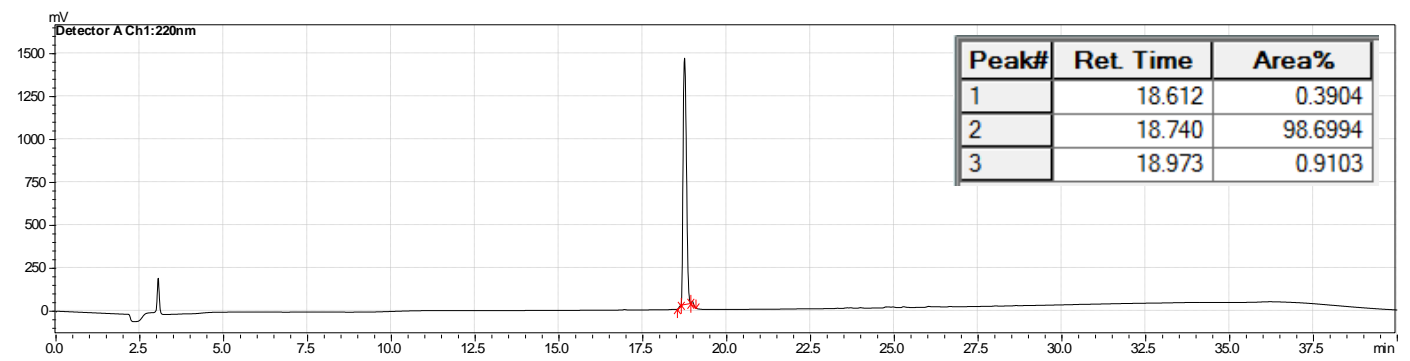




\section{XIP-L2NL (P17)}

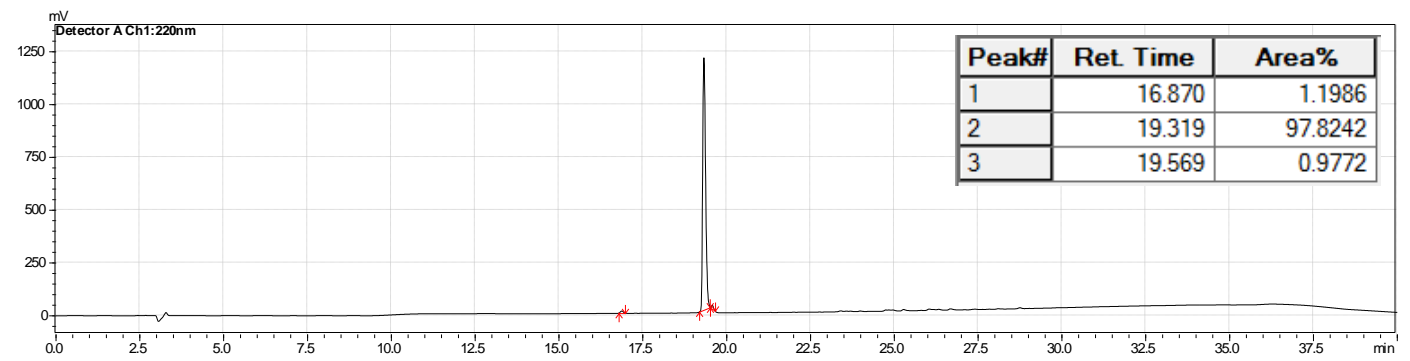

XIP-L2NV (P18)

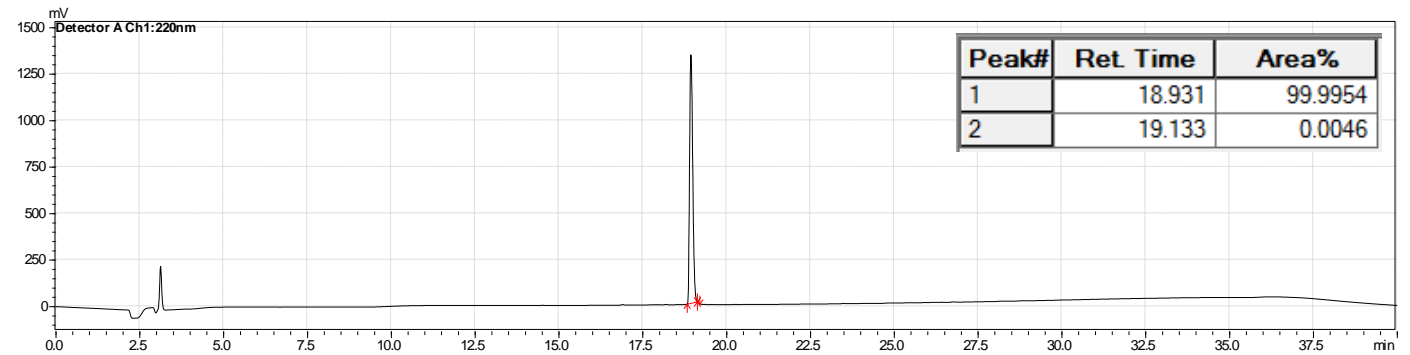

XIP-W4F (P19)

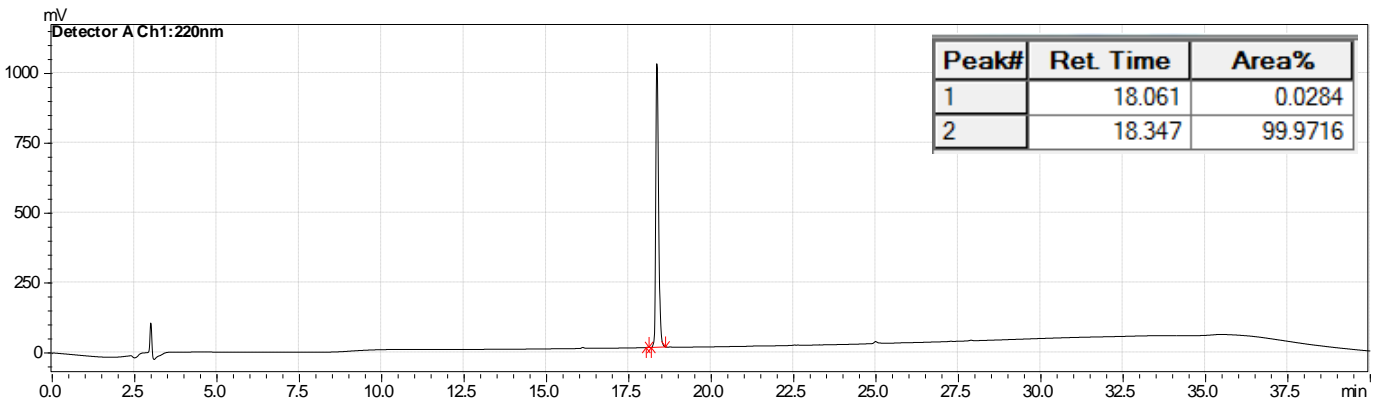

XIP-W4Y (P20)

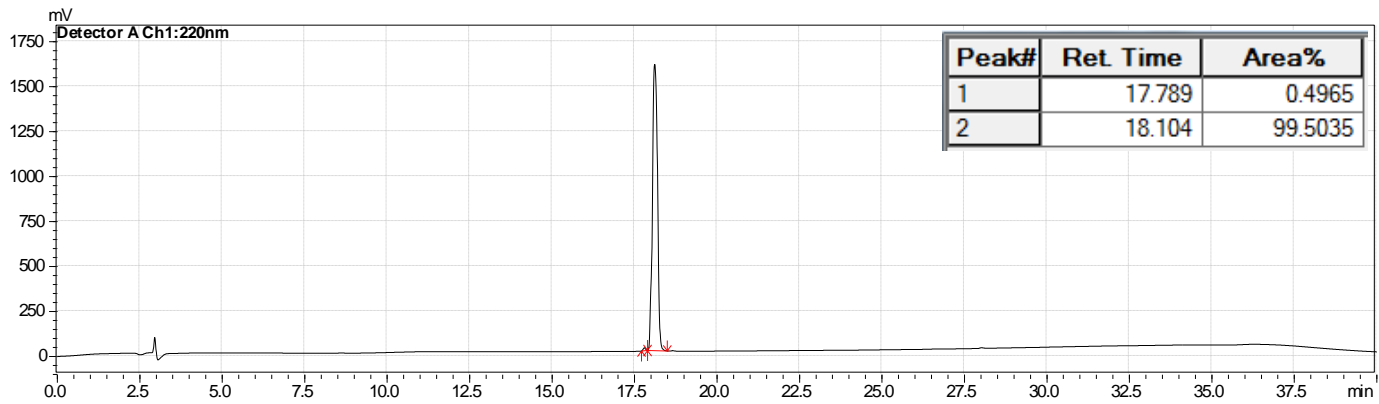


XIP-W4Cha (P21)

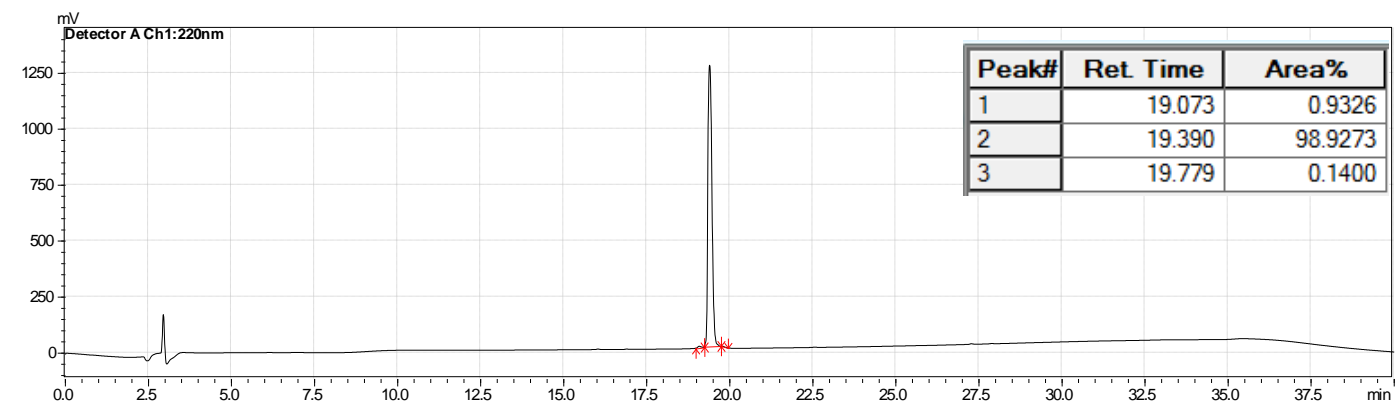

XIP-W5F (P22)

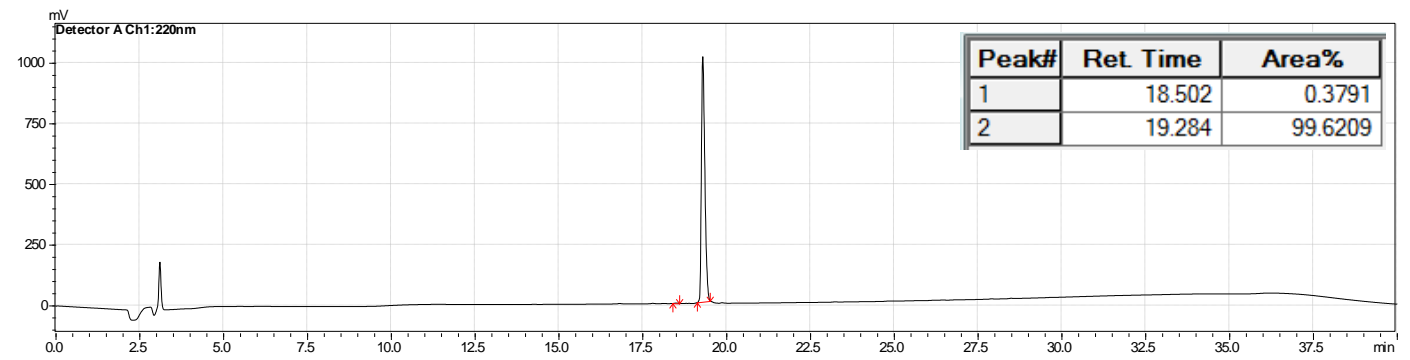

XIP-W5Y (P23)

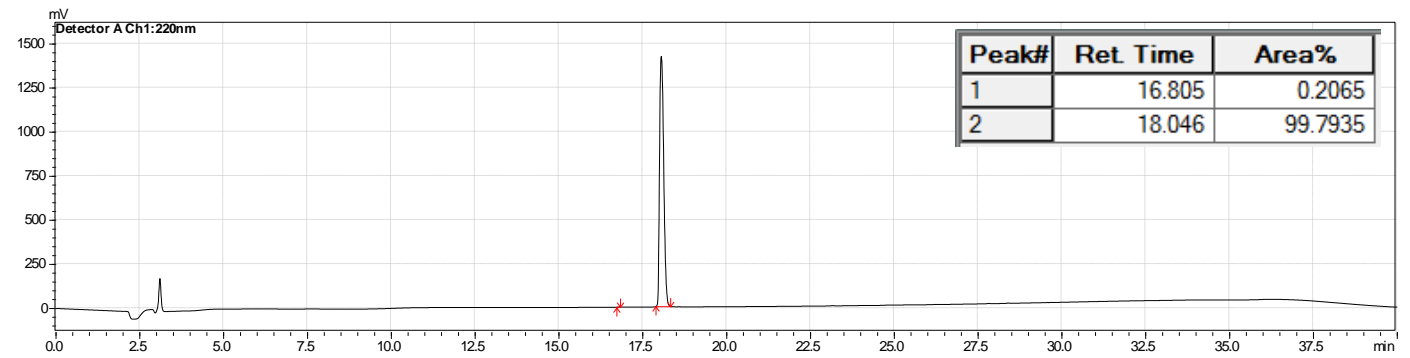

XIP-W5Cha (P24)

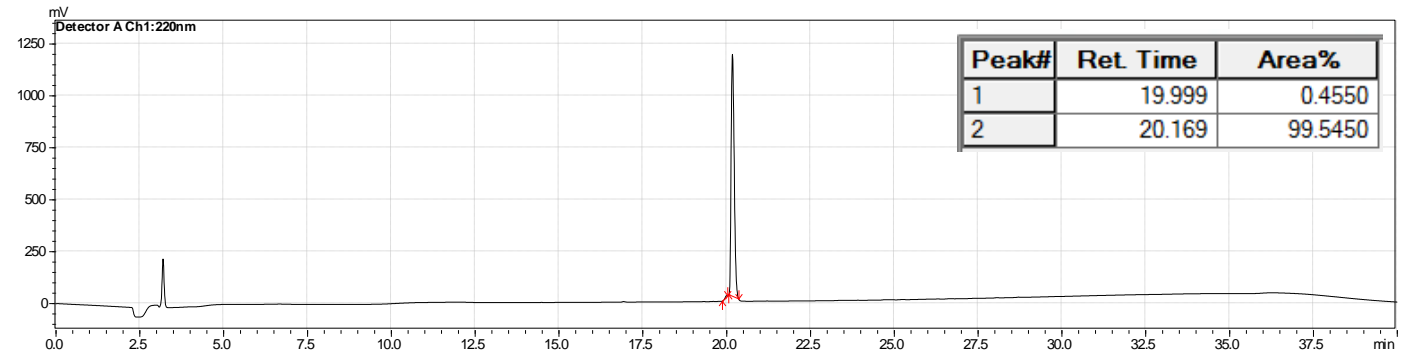


XIP-L7I (P25)

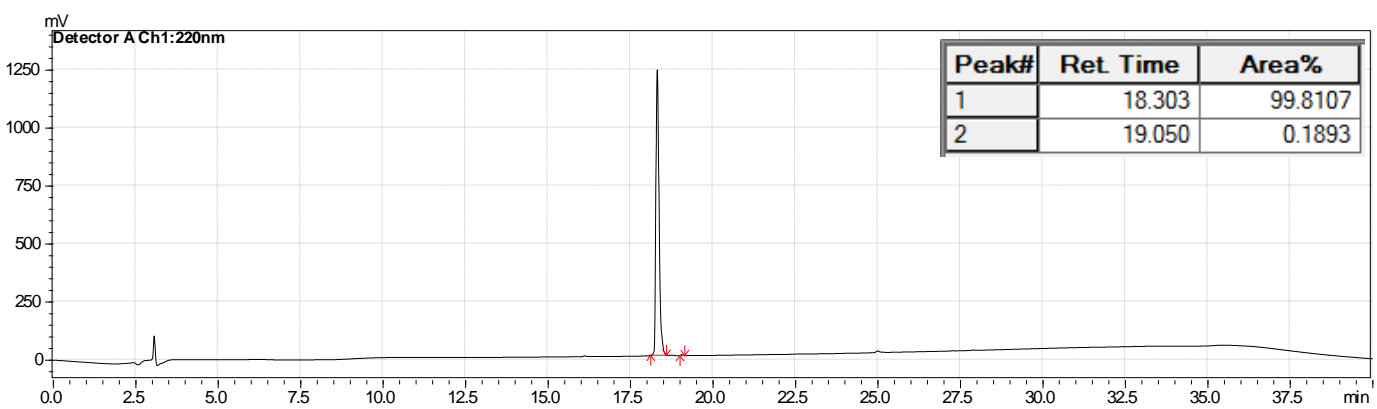

XIP-L7V (P26)

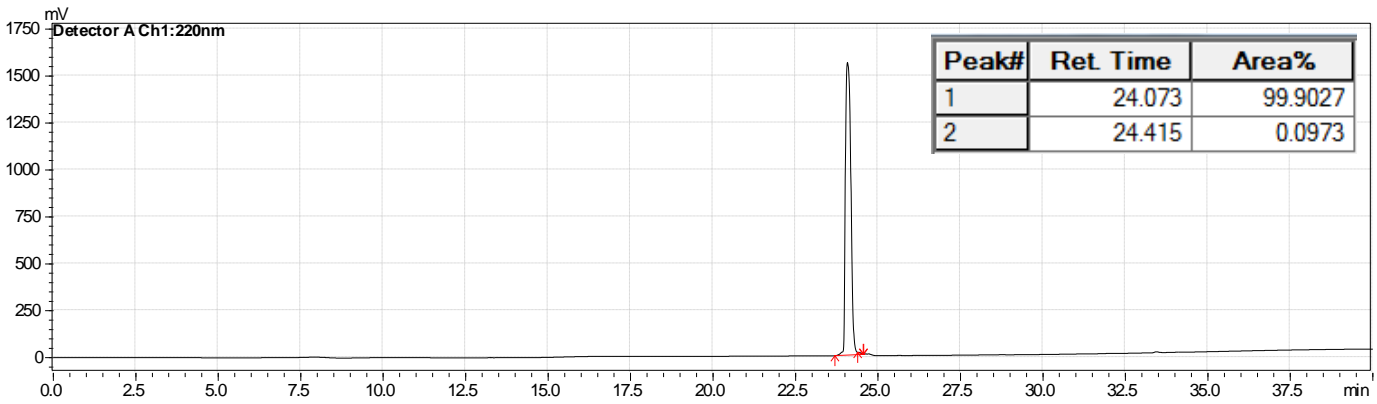

XIP-L7NL (P27)

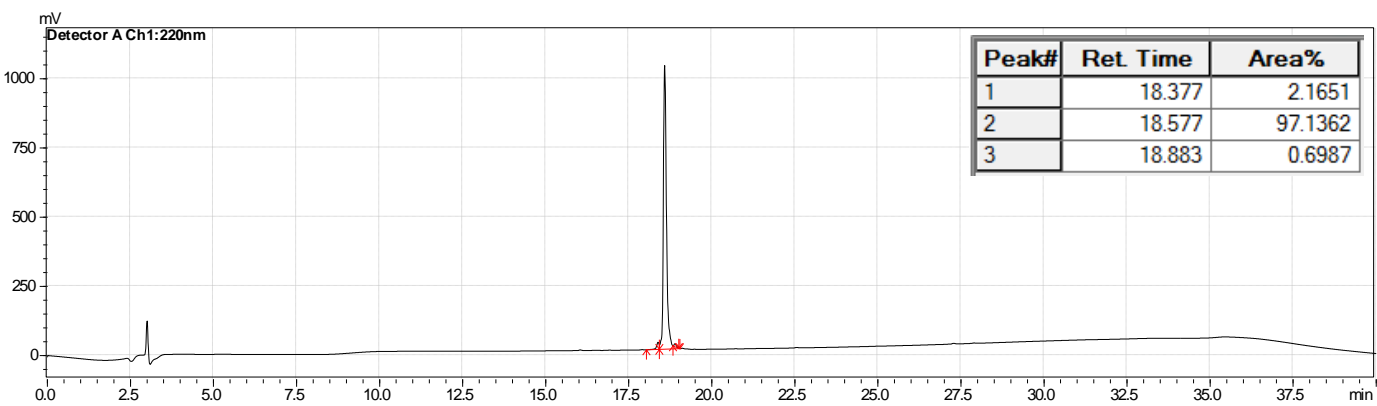

\section{XIP-L7NV (P28)}

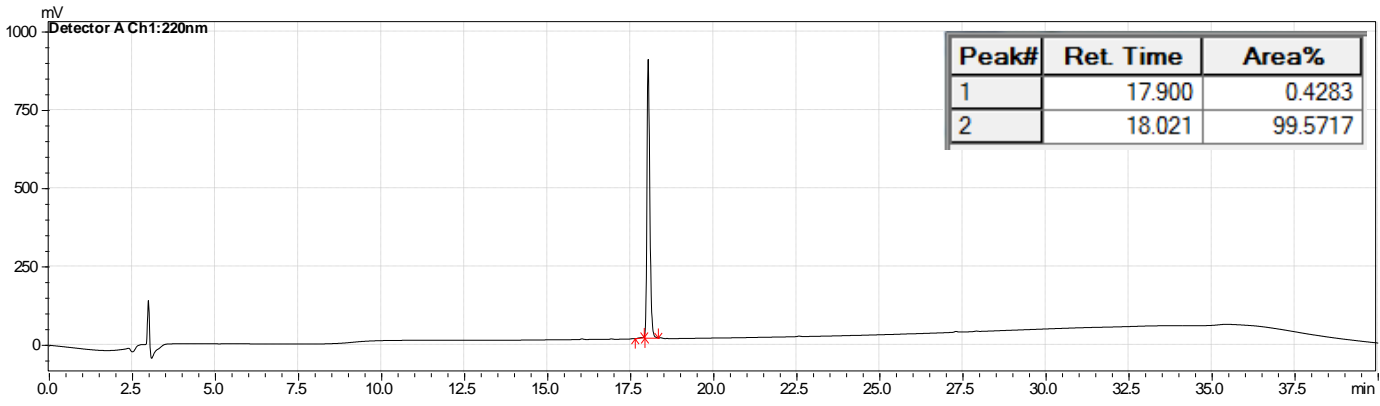


XIP-W4AL7A (P29)

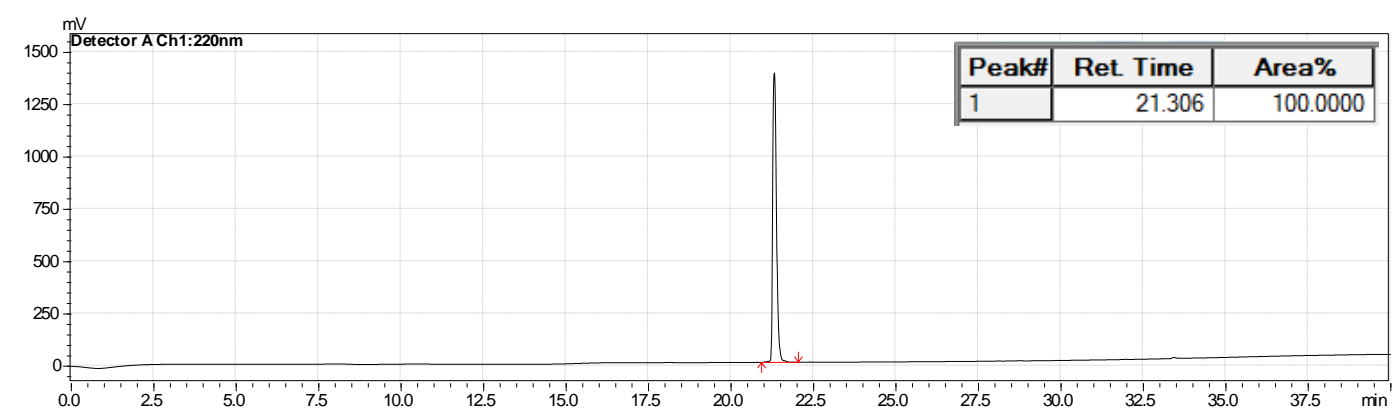

XIP-G1AD3AS6A (P30)

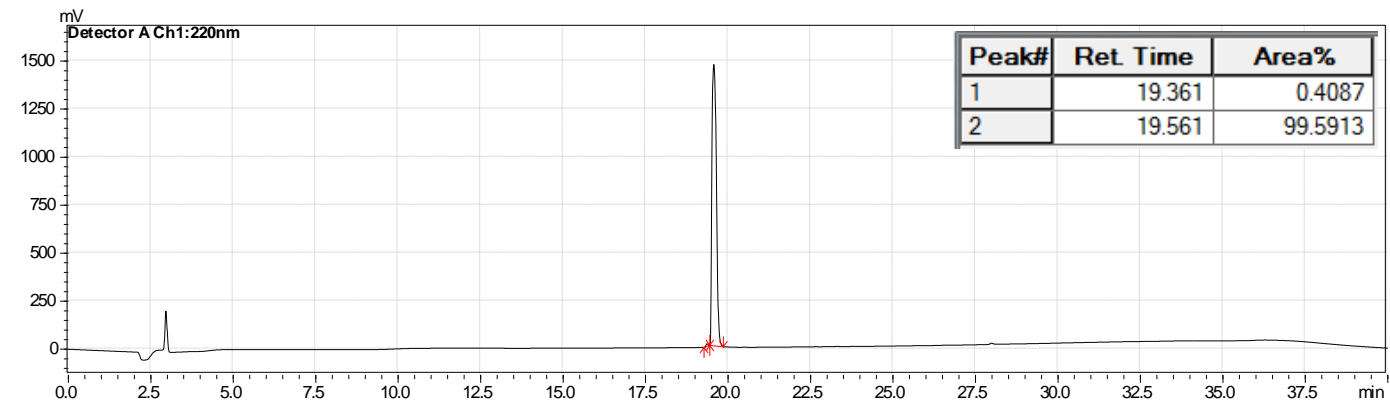

XIP-G1AD3AW4YS6A (P31)

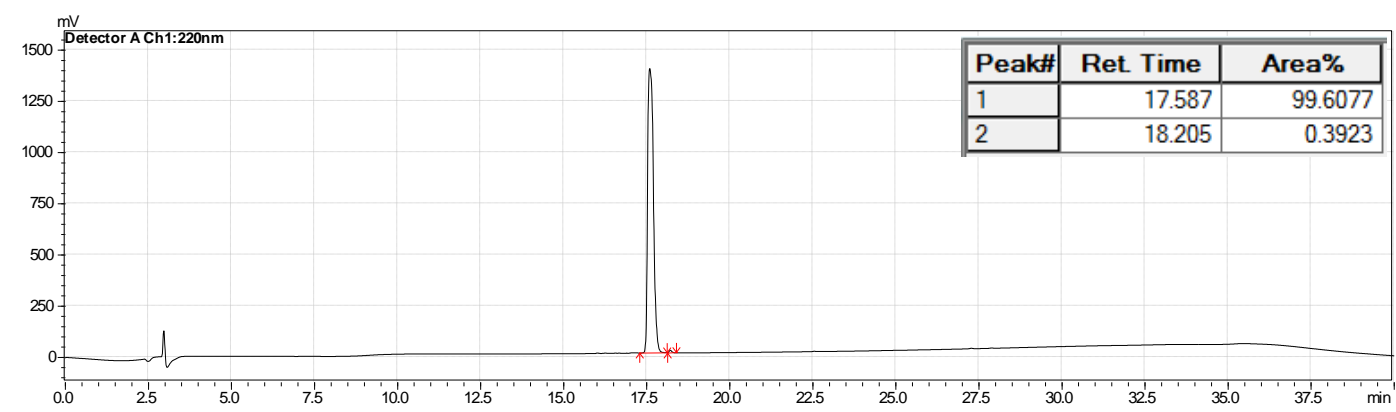

XIP-G1AD3AW4AS6A (P32)

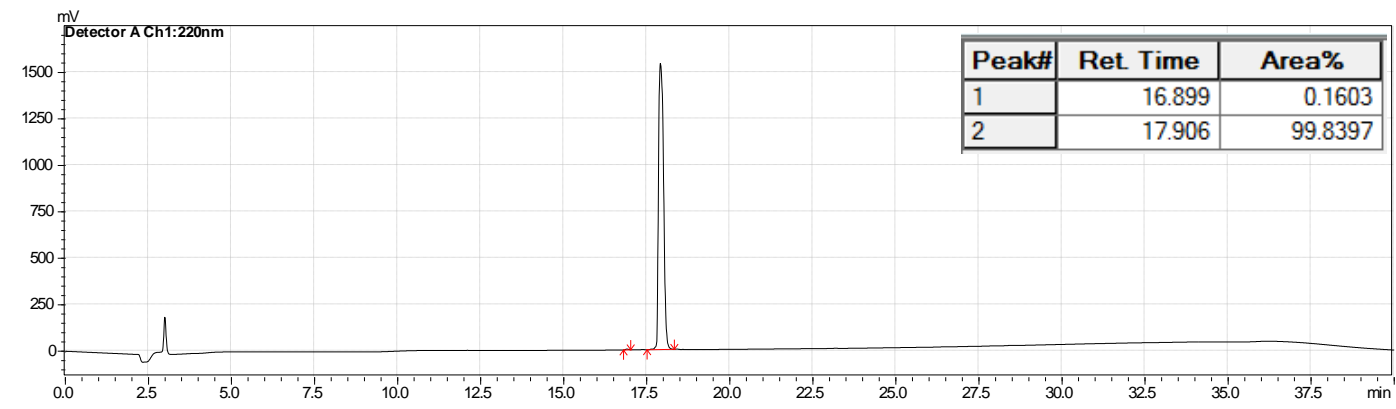


XIP-G1AD3AS6AL7A (P33)

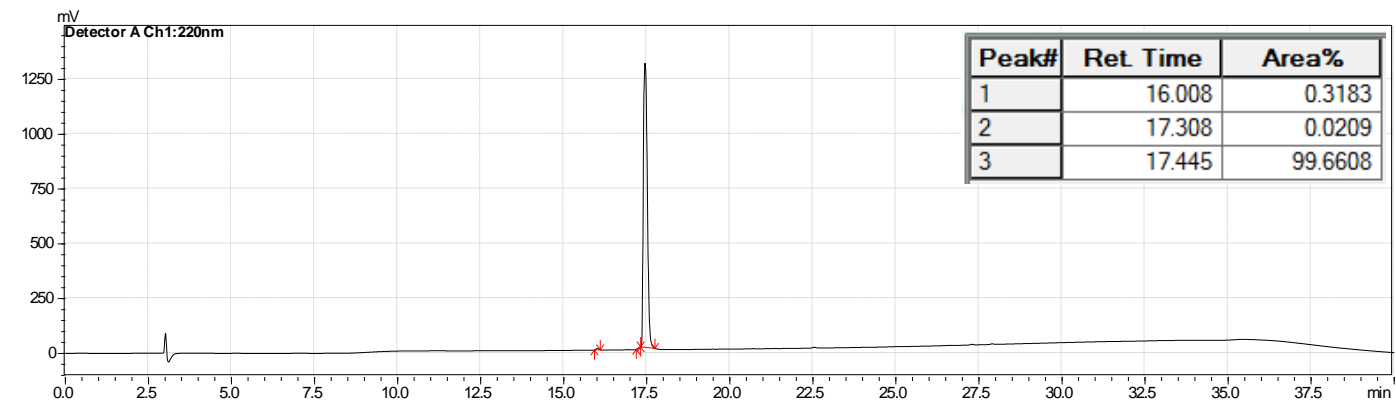

XIP-G1AD3AW4AS6AL7A (P34)

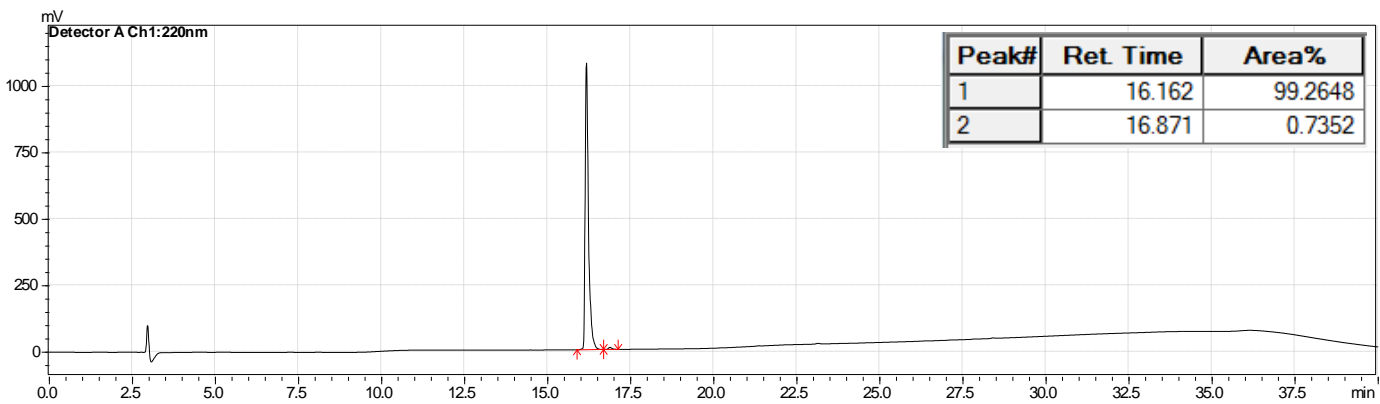

XIP-des-G1 (P35)

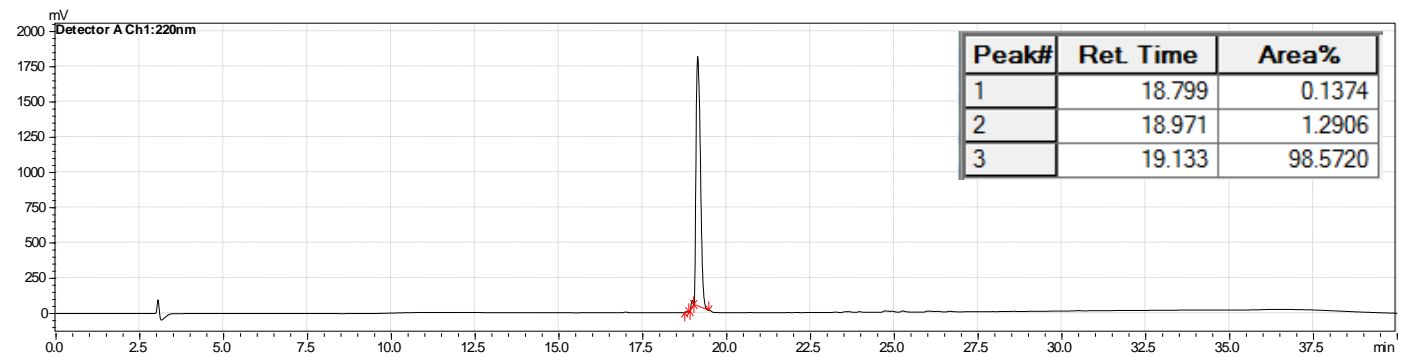

XIP-des-G1L2 (P36)

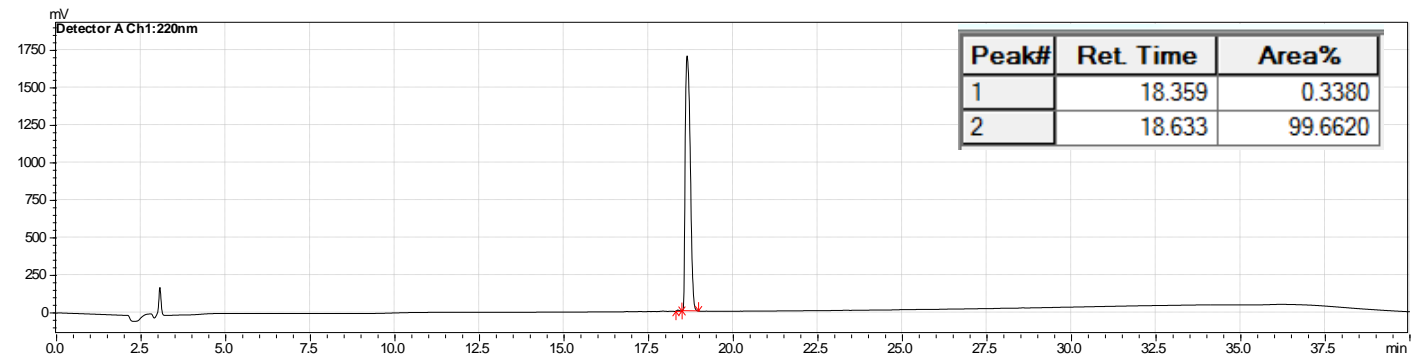


XIP-des-G1L2D3 (P37)

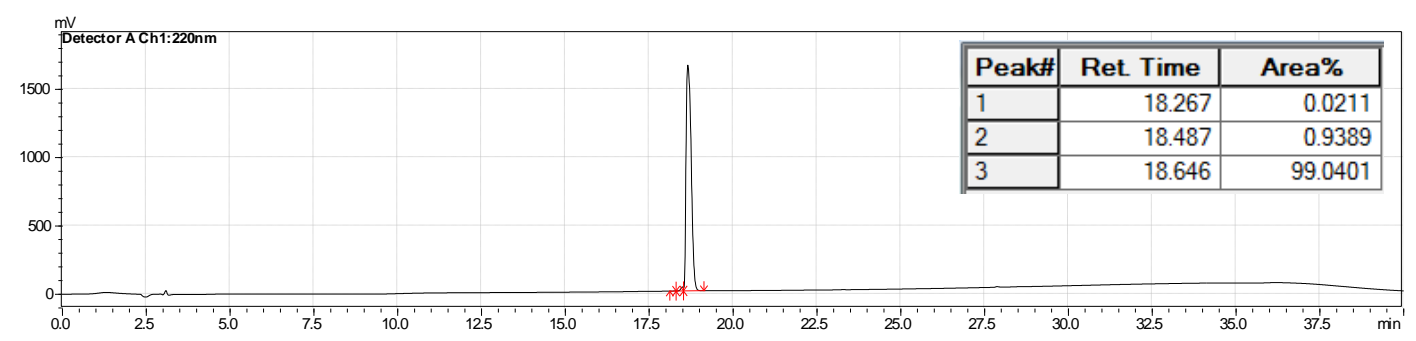

XIP-des-G1L2D3W4 (P38)

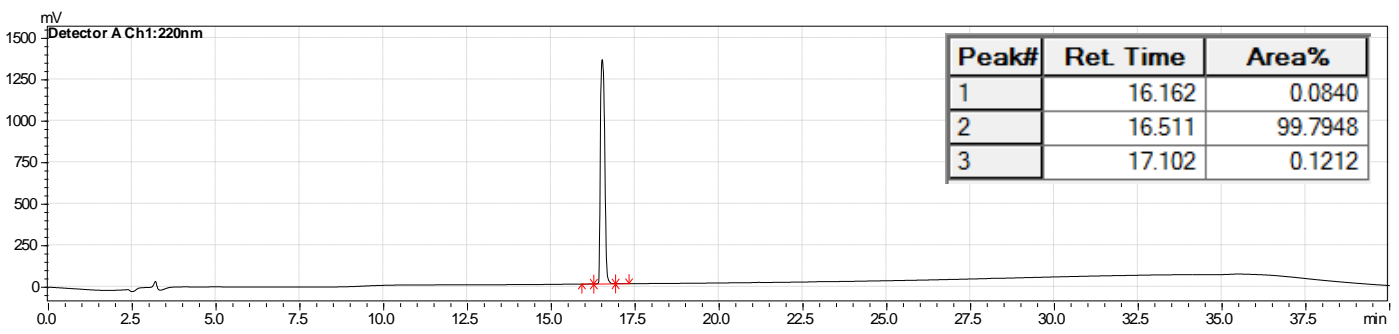

XIP-Des-G1L2D3W4W5 (P39)

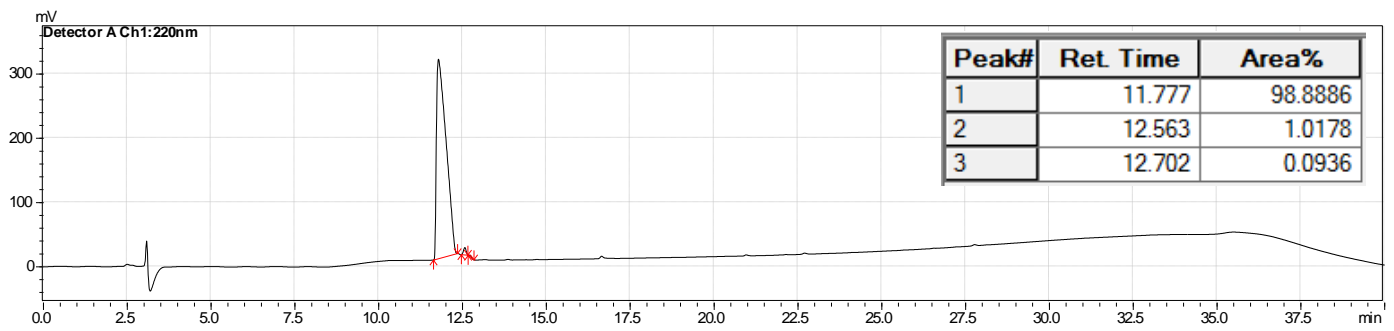

XIP-des-L7 (P40)

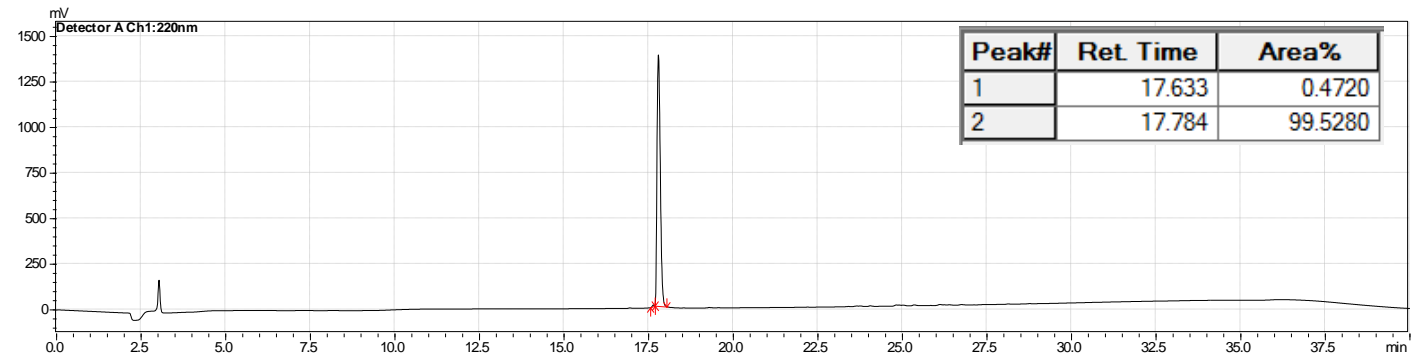

\section{XIP-des-S6L7 (P41)}

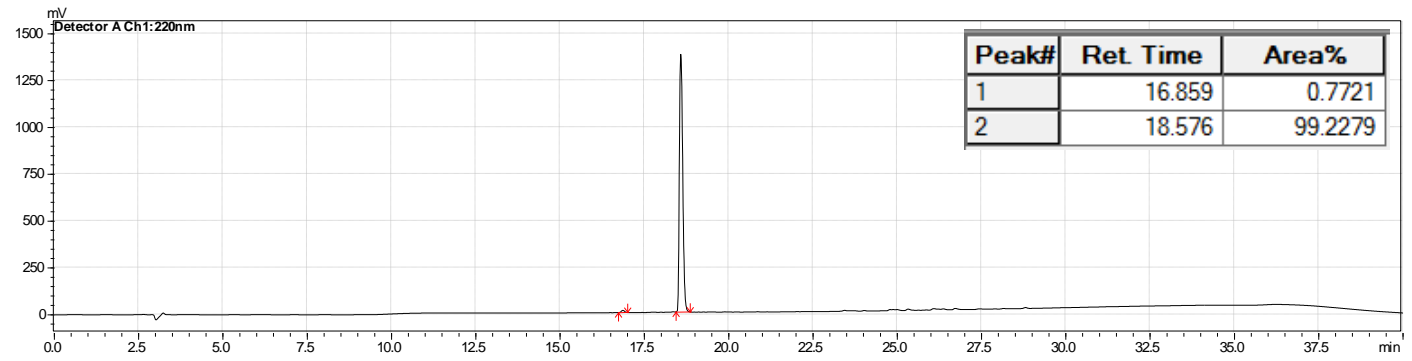


XIP-des-W5S6L7 (P42)

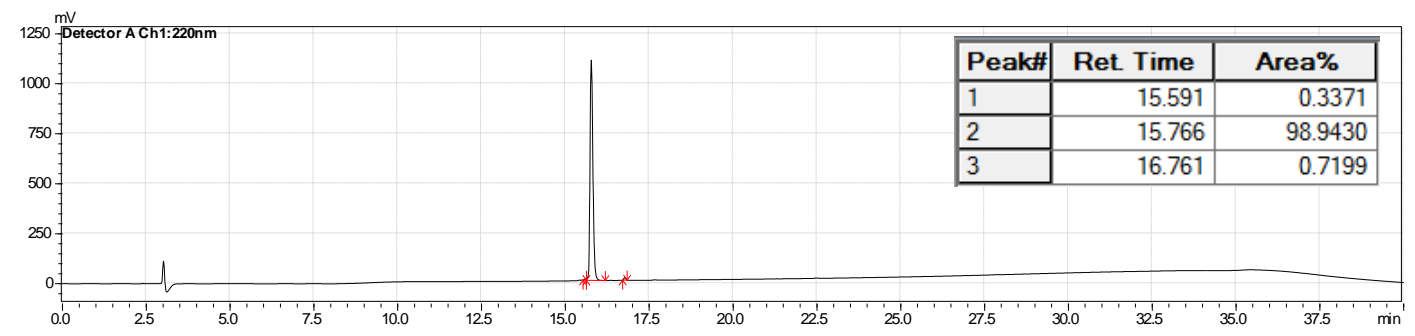

XIP-Des-W4W5S6L7 (P43)

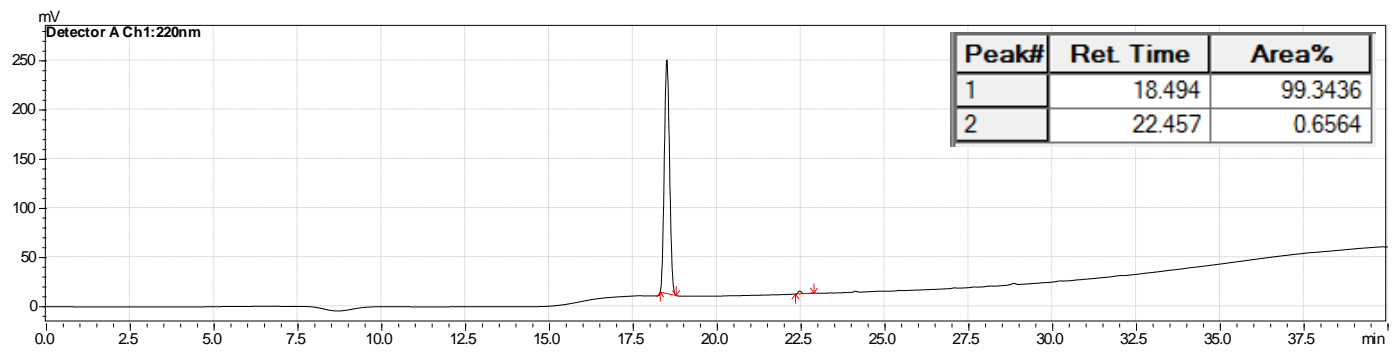

XIP-Des-G1L2D3L7 (P44)

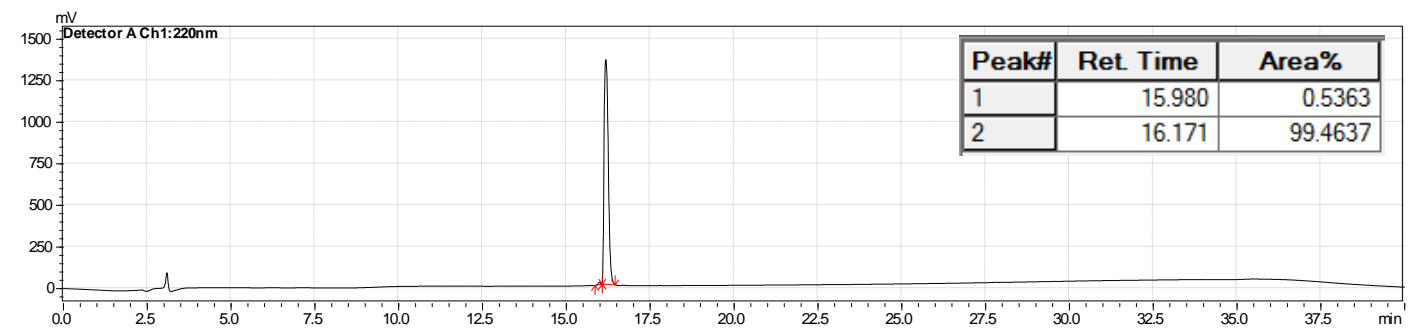

XIP-Des-G1L2D3W4L7 (P45)

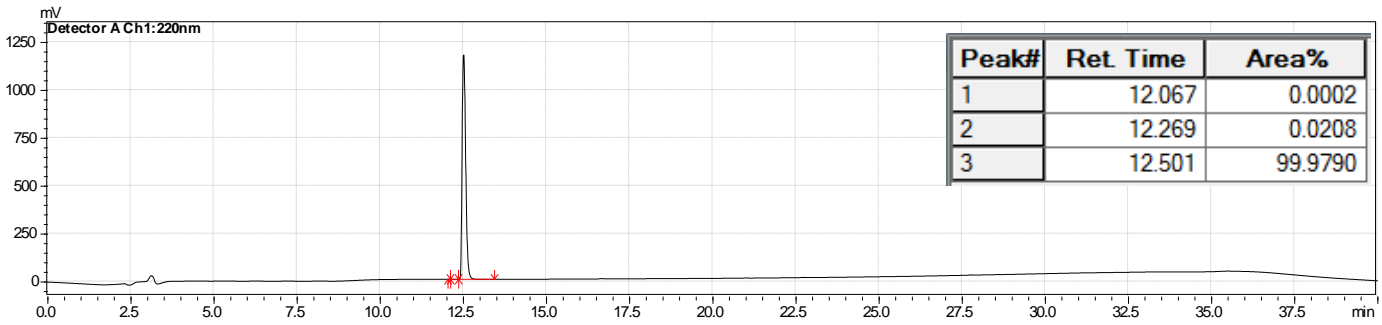


XIP-Des-G1L2D3S6L7 (P46)

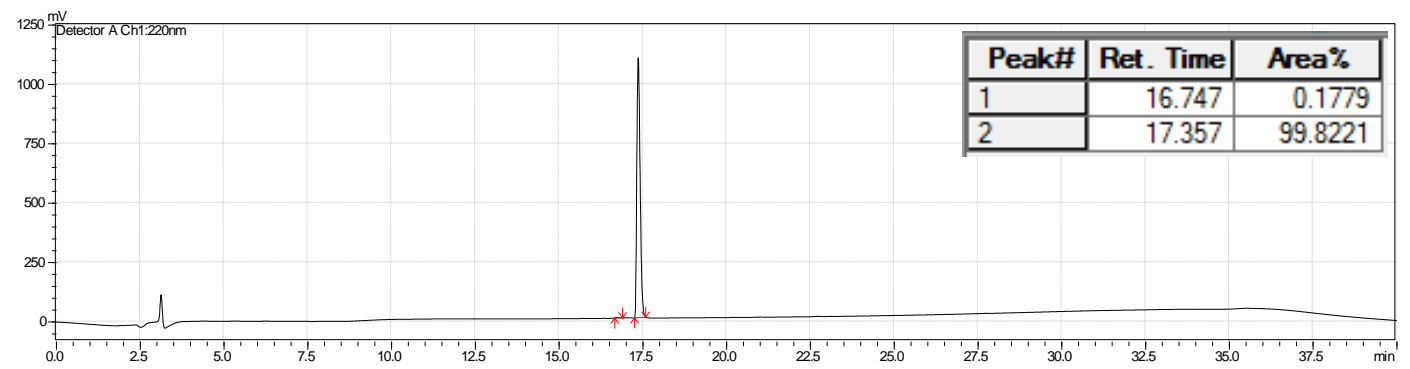




\section{MS and HPLC data for XIP analogs}

Table S-1. MS and HPLC data for XIP analogs.

\begin{tabular}{|c|c|c|c|c|}
\hline Compound Name & Sequence & $\begin{array}{c}\text { Calc. EM } \\
\mathbf{M H}^{1+}\end{array}$ & $\begin{array}{c}\text { Obs. EM } \\
\text { MH }^{1+}\end{array}$ & $\begin{array}{c}\text { Purity } \\
(\%)\end{array}$ \\
\hline XIP (P1) & GLDWWSL & 876.4250 & 876.4290 & $>99$ \\
\hline XIP-G1A (P2) & ALDWWSL & 890.4407 & 890.4381 & $>96$ \\
\hline XIP-L2A (P3) & GADWWSL & 834.3781 & 834.3740 & $>99$ \\
\hline XIP-D3A (P4) & GLAWWSL & 832.4352 & 832.4326 & $>99$ \\
\hline XIP-W4A (P5) & GLDAWSL & 761.3828 & 761.3817 & $>98$ \\
\hline XIP-W5A (P6) & GLDWASL & 761.3828 & 761.3828 & $>99$ \\
\hline XIP-S6A (P7) & GLDWWAL & 860.4301 & 860.4294 & $>99$ \\
\hline XIP-L7A (P8) & GLDWWSA & 834.3781 & 834.3756 & $>99$ \\
\hline XIP-12 (P9) & GIDWWSL & 876.4250 & 876.4232 & $>99$ \\
\hline XIP-d3 (P10) & GLdWWSL & 876.4250 & 876.4247 & $>98$ \\
\hline XIP-w4 (P11) & GLDwWSL & 876.4250 & 876.4238 & $>99$ \\
\hline XIP-w5 (P12) & GLDWwSL & 876.4250 & 876.4246 & $>96$ \\
\hline XIP-s6 (P13) & GLDWWsL & 876.4250 & 876.4211 & $>99$ \\
\hline XIP-17 (P14) & GLDWWSl & 876.4250 & 876.4210 & $>99$ \\
\hline XIP-L2I (P15) & GIDWWSL & 876.4250 & 876.4217 & $>99$ \\
\hline XIP-L2V (P16) & GVDWWSL & 862.4094 & 862.4103 & $>98$ \\
\hline XIP-L2NL (P17) & GnLDWWSL & 876.4250 & 876.4269 & $>97$ \\
\hline XIP-L2NV (P18) & GnVDWWSL & 862.4094 & 862.4112 & $>99$ \\
\hline XIP-W4F (P19) & GLDFWSL & 837.4141 & 837.4156 & $>99$ \\
\hline XIP-W4Y (P20) & GLDWYSL & 853.4090 & 853.4118 & $>99$ \\
\hline XIP-W4Cha (P21) & GLDChaWSL & 843.4611 & 843.4621 & $>98$ \\
\hline XIP-W5F (P22) & GLDWFSL & 837.4141 & 837.4130 & $>99$ \\
\hline XIP-W5Y (P23) & GLDWYSL & 853.4090 & 853.4071 & $>99$ \\
\hline XIP-W5Cha (P24) & GLDWChaSL & 843.4611 & 843.4589 & $>99$ \\
\hline XIP-L7I (P25) & GLDWWSI & 876.4250 & 876.4234 & $>99$ \\
\hline XIP-L7V (P26) & GLDWWSV & 862.4094 & 862.4072 & $>99$ \\
\hline XIP-L7NL (P27) & GLDWWSnL & 876.4250 & 876.4256 & $>97$ \\
\hline XIP-L7NV (P28) & GLDWWSnV & 862.4094 & 862.4097 & $>99$ \\
\hline XIP-W4AL7A (P29) & GLDAWSA & 830.4559 & 830.4537 & $>99$ \\
\hline XIP-G1AD3AS6A (P30) & ALAWWAL & 719.3359 & 719.3374 & $>99$ \\
\hline XIP-G1AD3AW4YS6A (P31) & ALAYWAL & 807.4400 & 807.4418 & $>99$ \\
\hline XIP-G1AD3AW4AS6A (P32) & ALAAWAL & 715.4137 & 715.4154 & $>99$ \\
\hline XIP-G1AD3AS6AL7A (P33) & ALAWWAA & 788.4090 & 788.4100 & $>99$ \\
\hline XIP-G1AD3AW4AS6AL7A (P34) & ALAAWAA & 673.3668 & 673.3678 & $>99$ \\
\hline
\end{tabular}

$\mathrm{EM}=$ Exact Mass. 
Table S-2. MS and HPLC data for XIP analogs.

\begin{tabular}{lcccc}
\hline \multicolumn{1}{c}{ Compound Name } & Sequence & $\begin{array}{c}\text { Calc. EM } \\
\mathbf{M H}^{\mathbf{1 +}}\end{array}$ & $\begin{array}{c}\text { Obs. EM } \\
\mathbf{M H}^{\mathbf{1 +}}\end{array}$ & $\begin{array}{c}\text { Purity } \\
(\boldsymbol{\%})\end{array}$ \\
\hline XIP & GLDWWSL & 876.4250 & 876.4290 & $>99$ \\
XIP-des-G1 (P35) & LDWWSL & 819.4036 & 819.4029 & $>98$ \\
XIP-des-G1L2 (P36) & DWWSL & 706.3195 & 706.3184 & $>99$ \\
XIP-des-G1L2D3 (P37) & WWSL & 591.2926 & 591.2908 & $>99$ \\
XIP-des-G1L2D3W4 (P38) & WSL & 405.2132 & 405.2149 & $>99$ \\
XIP-des-G1L2D3W4W5 (P39) & SL & $241.1159(+\mathrm{Na})$ & 241.1156 & $>98$ \\
XIP-des-L7 (P40) & GLDWWS & 763.3410 & 763.3391 & $>99$ \\
XIP-des-S6L7 (P41) & GLDWW & 676.3089 & 676.3070 & $>99$ \\
XIP-des-W5S6L7 (P42) & GLDW & 490.2296 & 490.2281 & $>98$ \\
XIP-des-W4W5S6L7 (P43) & GLD & $326.1323(+\mathrm{Na})$ & 326.1320 & $>99$ \\
XIP-des-G1L2D3L7 (P44) & WWS & $500.1904(+\mathrm{Na})$ & 500.1883 & $>99$ \\
XIP-des-G1L2D3W4L7 (P45) & WS & $314.1111(+\mathrm{Na})$ & 314.1108 & $>99$ \\
XIP-des-G1L2D3S6L7 (P46) & WW & $413.1584(+\mathrm{Na})$ & 413.1582 & $>99$ \\
\hline EM-Exat MaS5. & & & &
\end{tabular}

$\mathrm{EM}=$ Exact Mass. 


\section{Primary reporter gene assay data}

\section{Initial agonism screening against $S$. mutans SMCOM2 (Pcomx::lacZ)}

Agonism assays were performed at $100 \mu \mathrm{M}$ concentration. XIP was used as the positive control (100\%) with DMSO as the negative control (0\%). Percent (\%) ComX activation was measured by normalizing the Miller units obtained for each peptide to that of XIP. All peptides were screened in triplicates over three separate trials. Error bars indicate standard error of the mean of nine values.

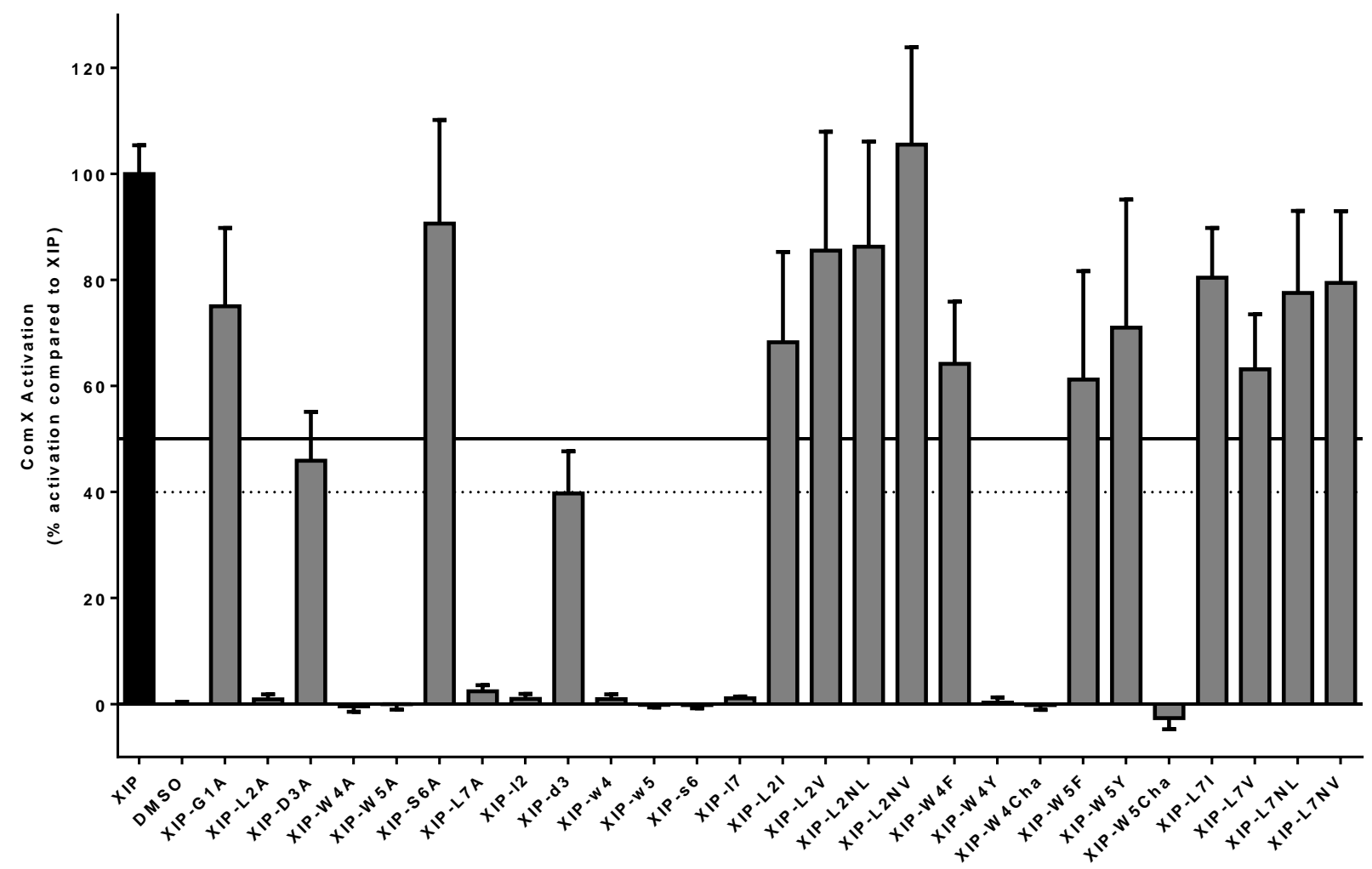

Figure S-1. Primary agonism screening assay data for the XIP analogs. Peptides that exhibited over 50\% activation were further evaluated to determine their $\mathrm{EC}_{50}$ while peptides that exhibited less than $40 \%$ activation were evaluated as potential competitive inhibitors. 


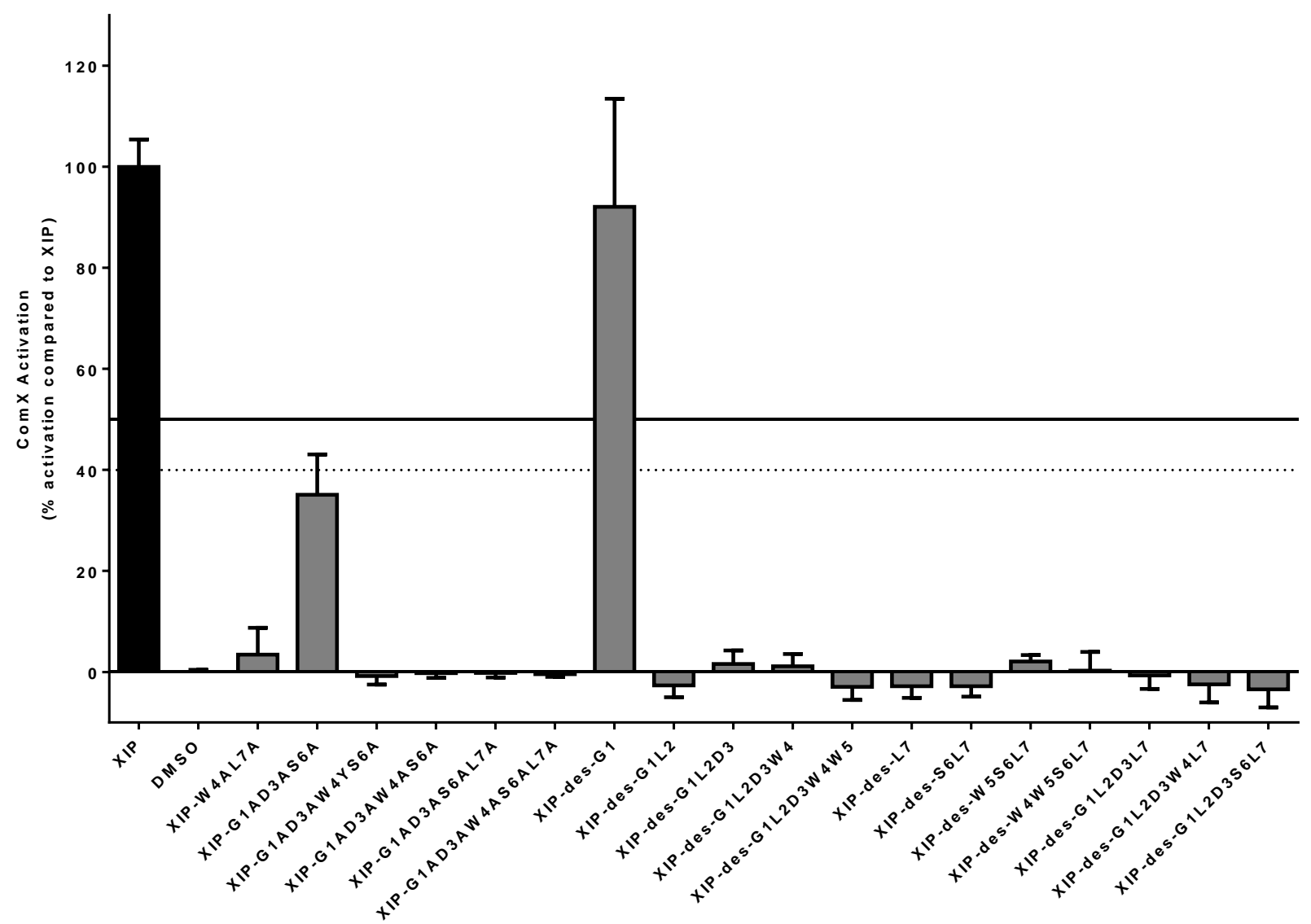

Figure S-2. Primary agonism screening assay data for the XIP analogs. Peptides that exhibited over 50\% activation were further evaluated to determine their $\mathrm{EC}_{50}$ while peptides that exhibited less than $40 \%$ activation were evaluated as potential competitive inhibitors. 


\section{Initial antagonism screening against S. mutans SMCOM2 (Pcomx::lacZ)}

Antagonism assays were performed at $100 \mu \mathrm{M}$ concentration of peptides against $2 \mu \mathrm{M}$ concentration of XIP. XIP $(2 \mu \mathrm{M})$ was used as the positive control (100\%) with DMSO as the negative control (0\%). Percent (\%) ComX activation was measured by normalizing the Miller units obtained for each peptide to that of XIP. All peptides were screened in triplicates over three separate trials. Error bars indicate standard error of the mean of nine values.

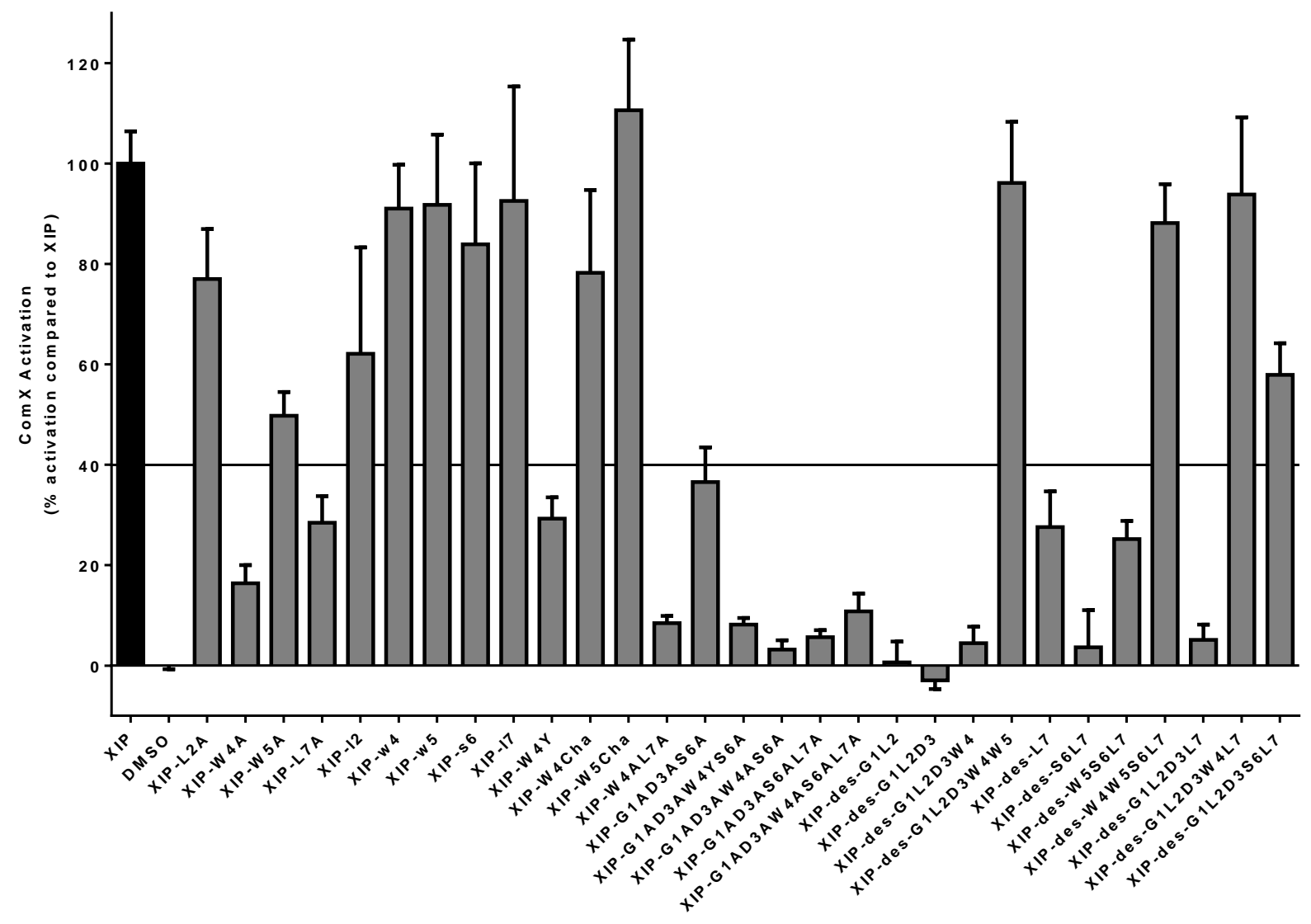

Figure S-3. Primary antagonism screening assay data for the XIP analogs. Peptides that exhibited less than $40 \%$ activation were further evaluated to determine their $\mathrm{IC}_{50}$. 

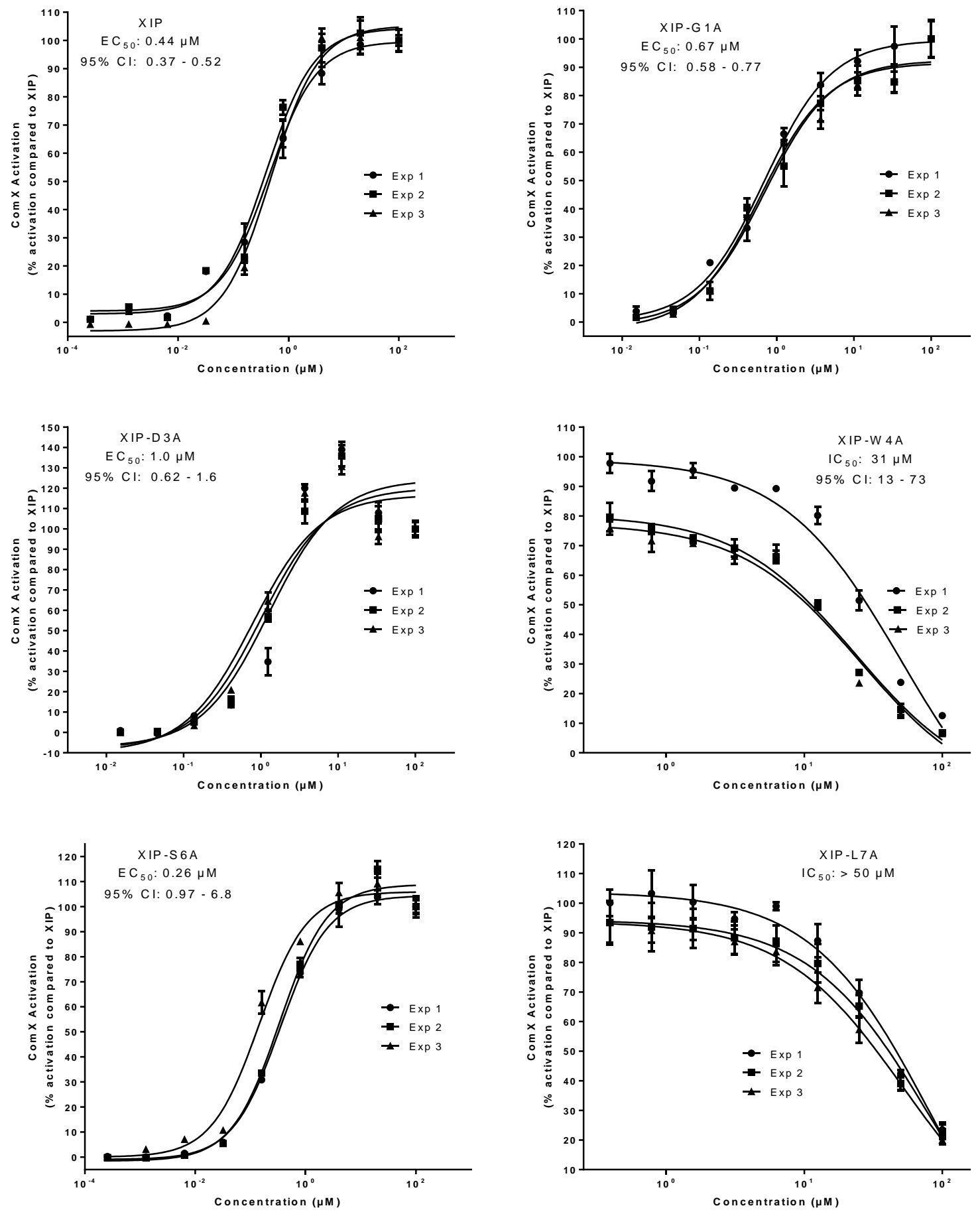

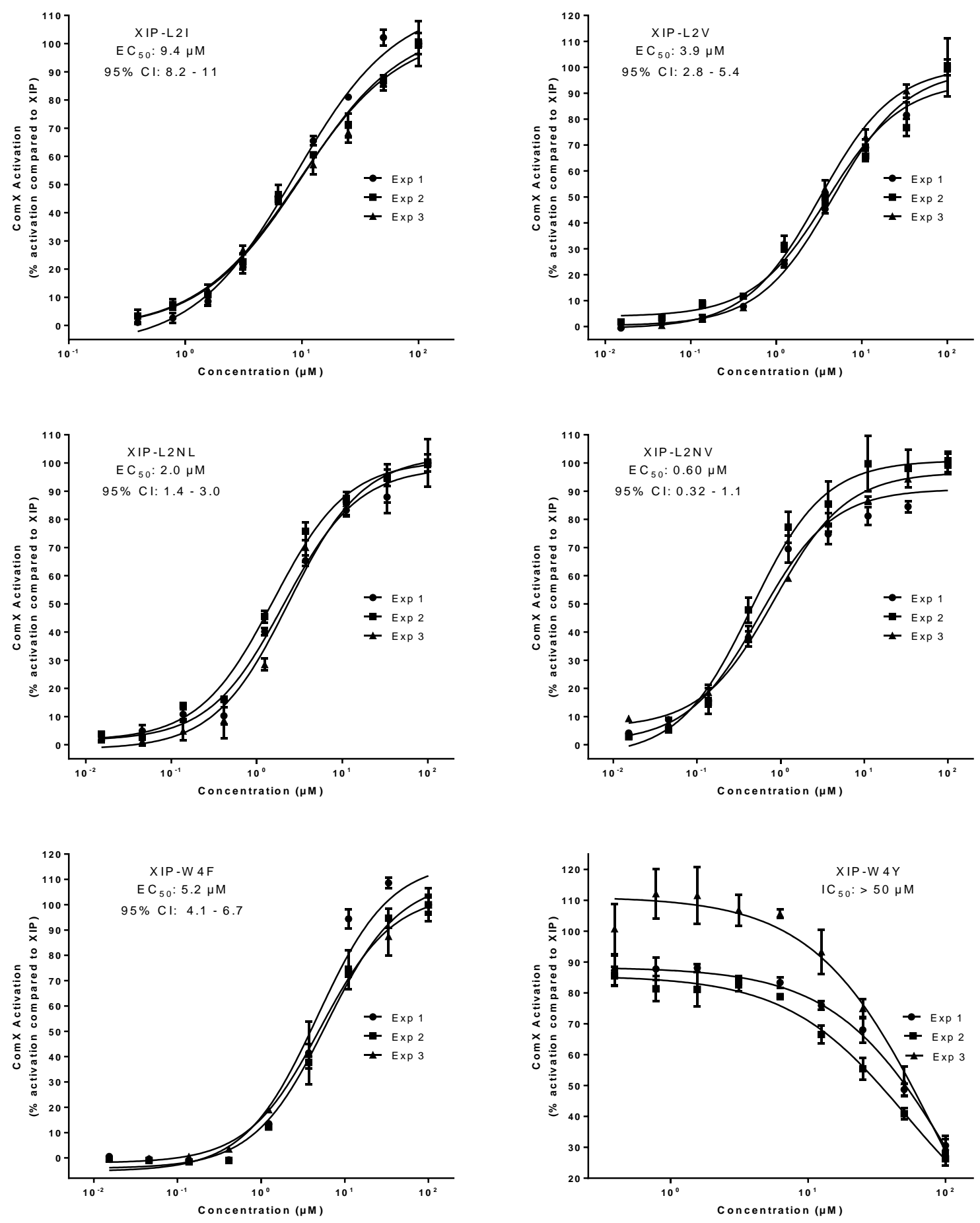

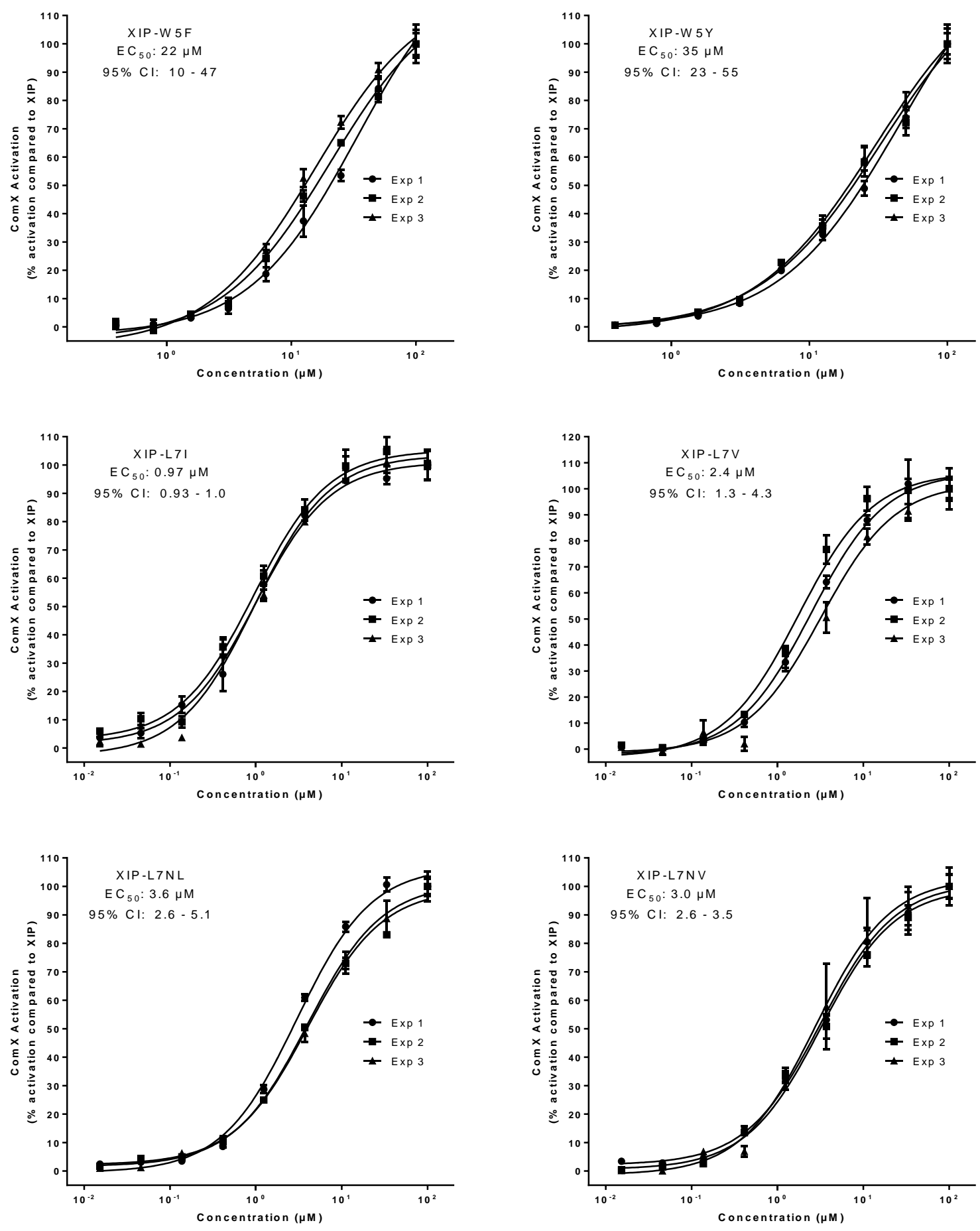

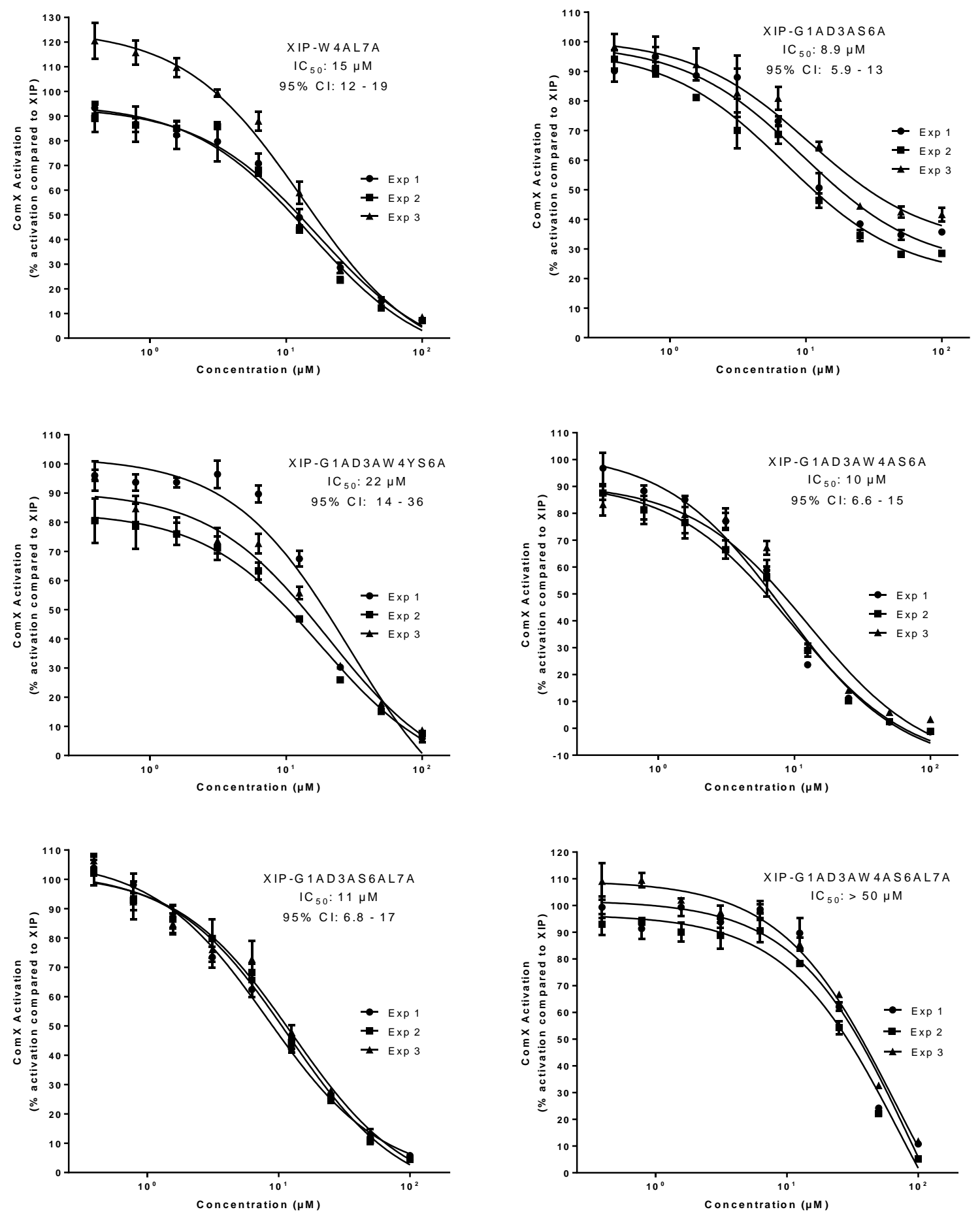

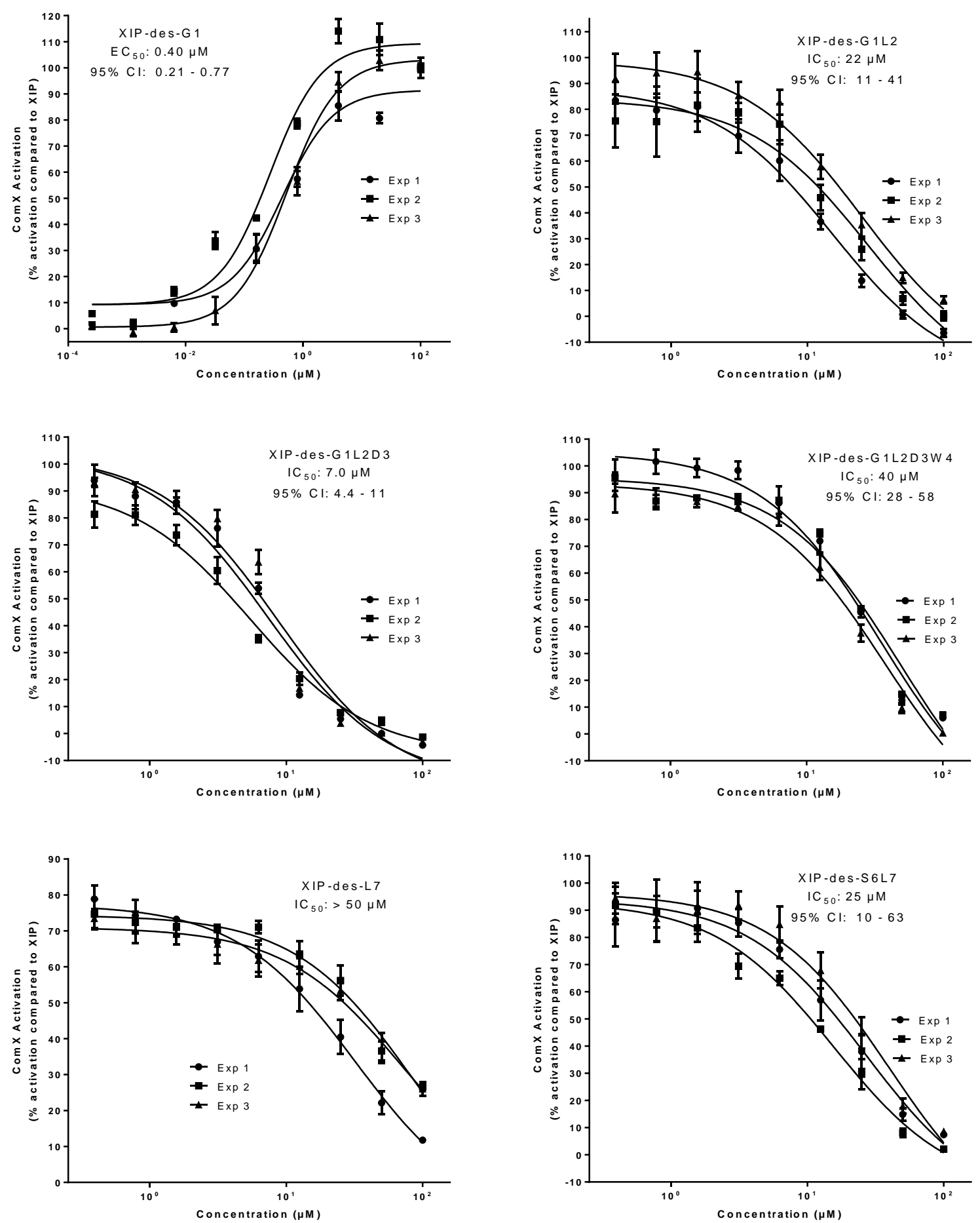

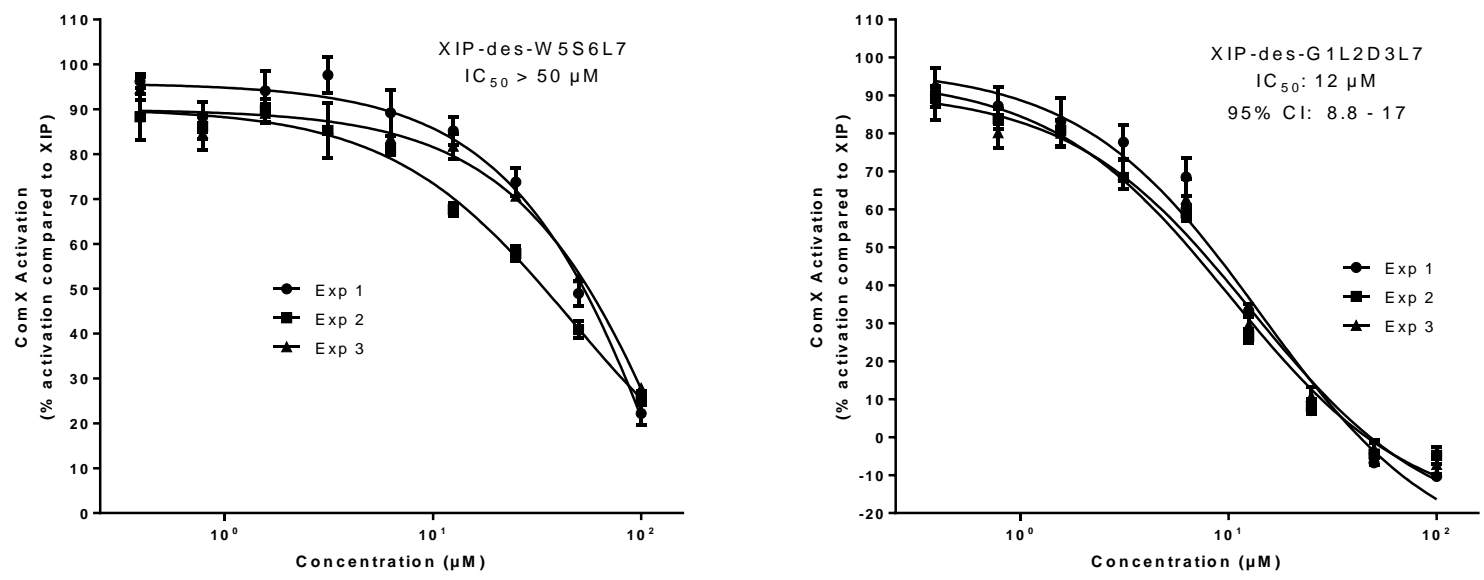


\section{Crystal violet biofilm formation assay}

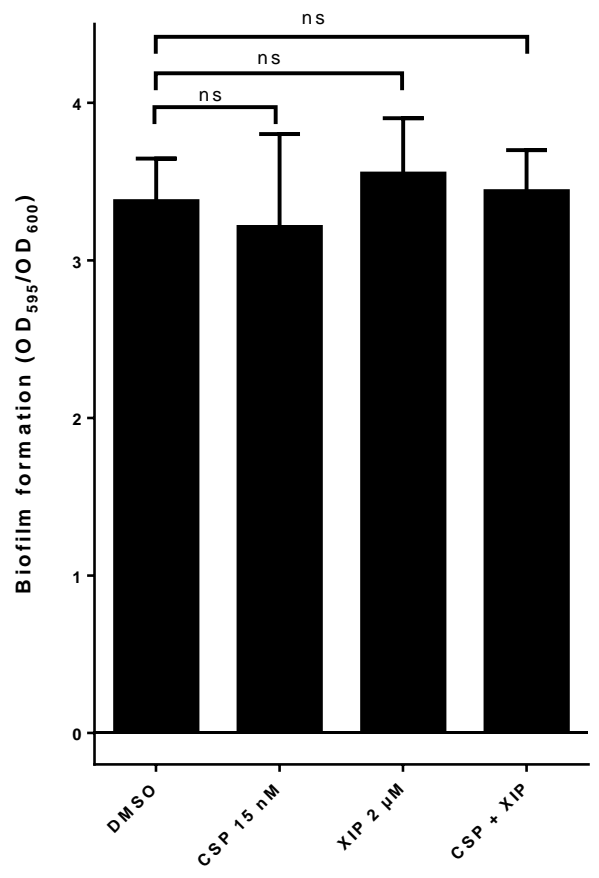

Figure S-4. Biofilm formation of $S$. mutans UA159 (wildtype) in the presence of 18-CSP (15 nM), XIP (2 $\mu \mathrm{M}), \mathrm{CSP}+\mathrm{XIP}$, or DMSO (negative control). No significant changes were observed in the presence of either CSP or XIP or both (CSP and XIP). ns, non-significant.

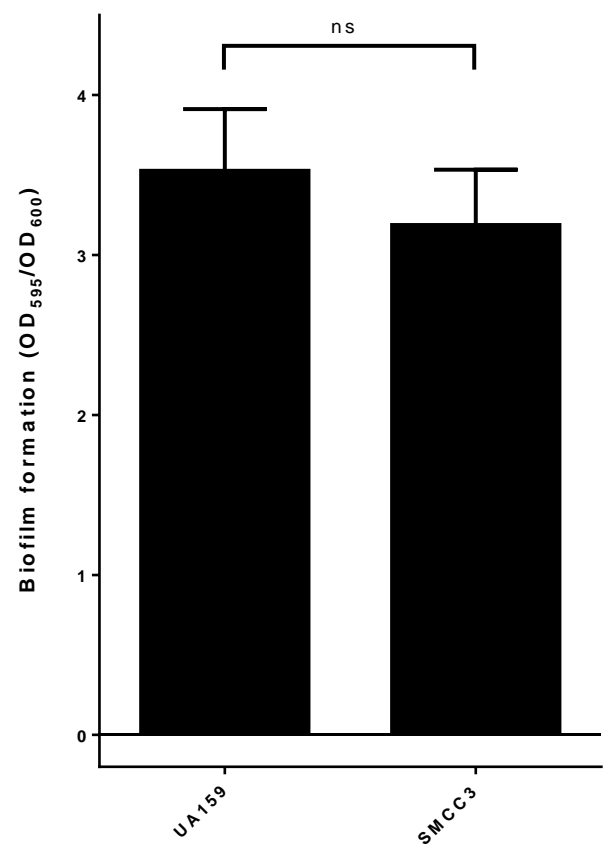

Figure S-5. Biofilm formation of $S$. mutans UA159 (wildtype) and SMCC3 ( $\Delta$ comC mutant). ns, nonsignificant. 


\section{$\underline{\text { Interspecies Inhibition assay }}$}
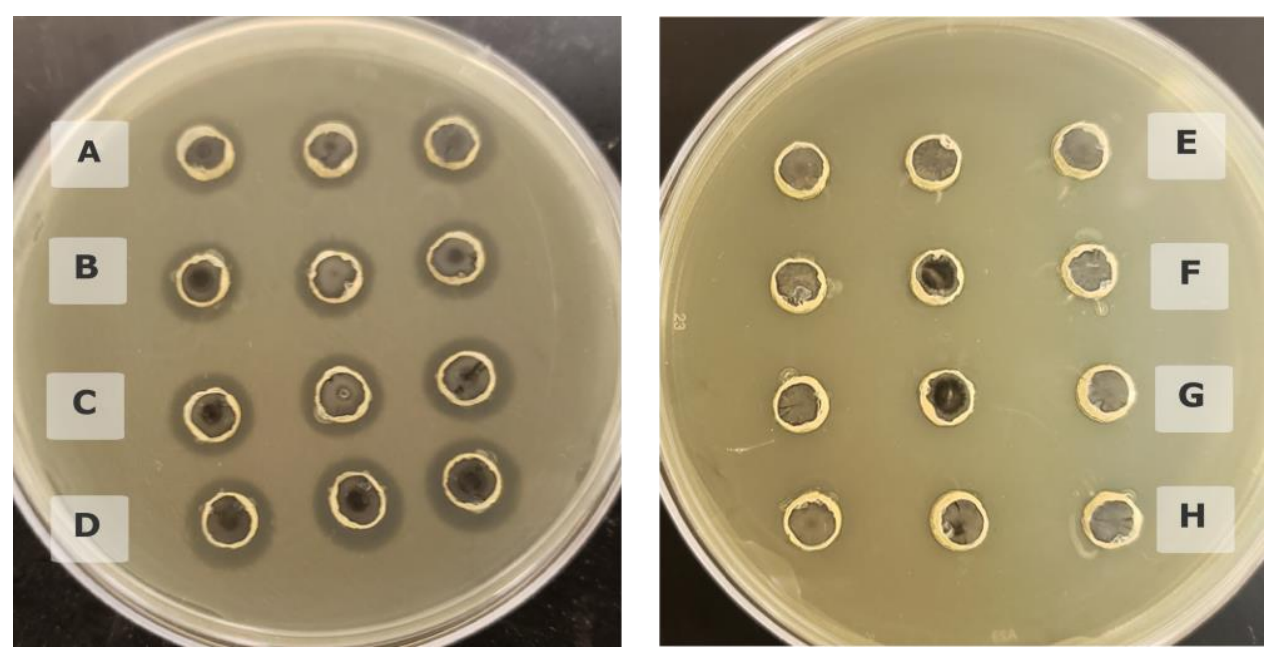

Figure S-6. Interspecies inhibition assay between S. mutans and S. anginosus. S. mutans SMCC3 ( $\triangle$ comC) was tested for its ability to inhibit the growth of S. anginosus ATCC 33397 when SMCC3 was treated with (A) $15 \mathrm{nM} 18-\mathrm{CSP}$, (B) $15 \mathrm{nM}$ 18-CSP + $2 \mu \mathrm{M}$ XIP, (C) $15 \mathrm{nM}$ 18-CSP + $100 \mu \mathrm{M}$ P32, (D) $15 \mathrm{nM} 18-$ $\mathrm{CSP}+2 \mu \mathrm{M}$ XIP + $100 \mu \mathrm{M}$ P32, (E) $2 \mu \mathrm{M}$ XIP, (F) $100 \mu \mathrm{M}$ P32, (G) $2 \mu \mathrm{M}$ XIP + $100 \mu \mathrm{M}$ P32, and (H) DMSO. Each assay was repeated on three separate days. 


\section{$\underline{\text { Lactic acid production assay }}$}

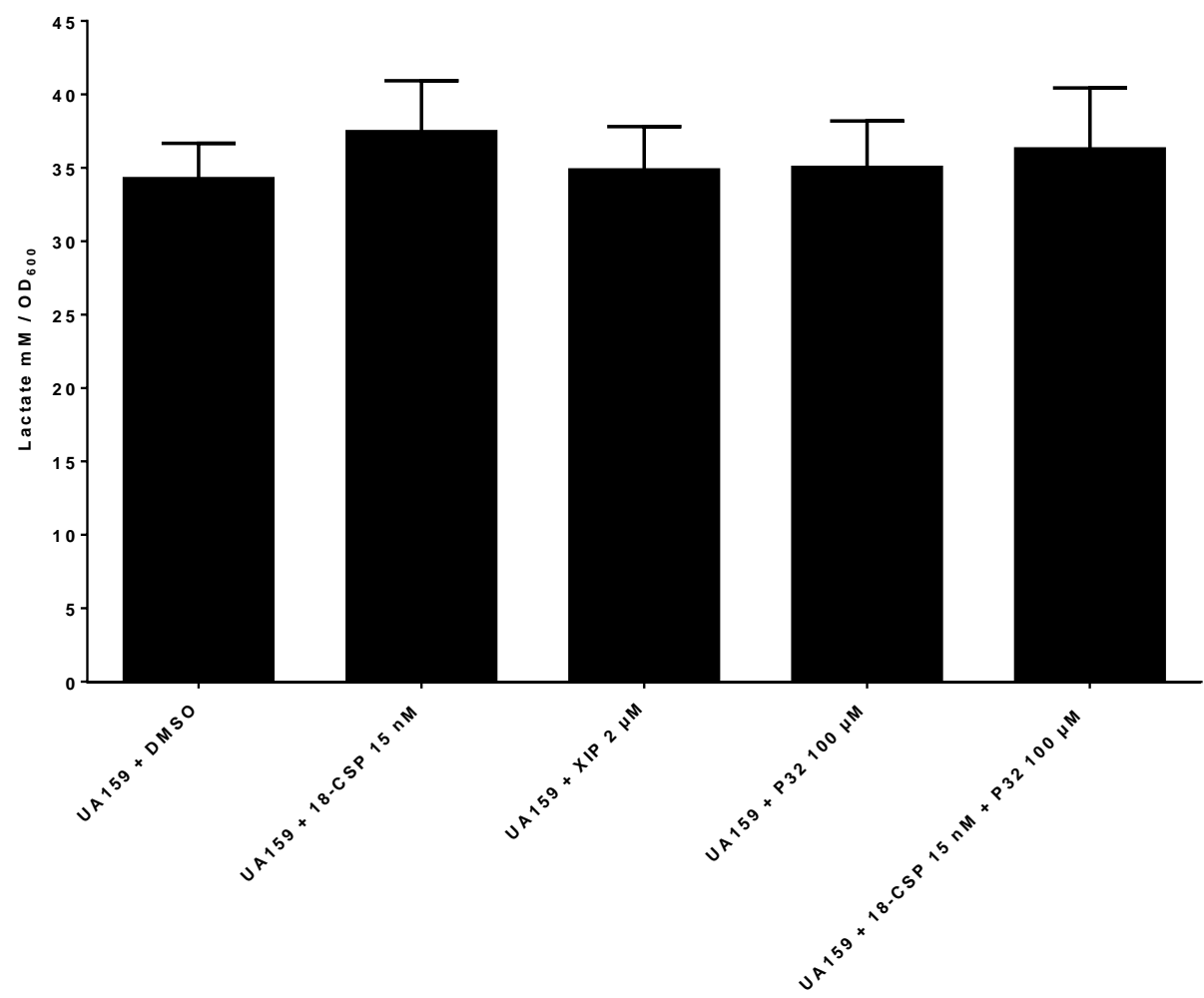

Figure S-7. Lactic acid production assay. S. mutans UA159 was treated with either DMSO (control), 18CSP, XIP, P32, or 18-CSP + P32, and lactic acid production was quantified using an EnzyChrome lactate assay. Similar levels of lactic acid were observed for all conditions. The assay was repeated in triplicate on three separate days. 